EstAg 30 (1995) 281-336

\title{
Consideraciones en torno al a priori del conocimiento
}

\begin{abstract}
"Todos creemos vivir directamente inmersos en el mundo que nos rodea, sentir sus objetos y acontecimientos con precisión, y vivir en el tiempo real y ordinario. Afirmo que todo eso no es más que una ilusión perceptiva, dado que todos nosotros nos enfrentamos al mundo desde un cerebro que se halla conectado con lo que está "ahí fuera" a través de unos cuantos millones de fibras nerviosas sensoriales. Esos son nuestros únicos canales de información, nuestras líneas vitales con la realidad. Estas fibras nerviosas sensoriales no son registradoras de alta fidelidad, dado que acentúan ciertas características del estímulo, mientras que desprecian otras. La neurona central es un contador de historias, por lo que respecta a las fibras nerviosas aferentes, y nunca resulta completamente fiable, permitiendo distorsiones de cualidad y de medida en una relación espacial forzada aunque isomórfica entre "fuera"y "dentro". La sensación es una abstracción, no una réplica del mundo real”. (Mountcatle [1975]; en J.Eccles, El yo y su cerebro, pág. 285).
\end{abstract}

\section{I.- INTRODUCCION *}

Resulta siempre apasionante, cuando tratamos de comprender la aventura del pensamiento a lo largo de los siglos, detenerse en sus orígenes, en el surgir del pensamiento racional con los presocráticos.

Frente a lo que pudiera ser aquella sociedad cerrada con sus cuadros de referencia basados en el mito, surge el filósofo, surge la racionalidad como pregunta crítica y como intento de comprender el mundo y comprendernos a nosotros mismos. Como dice Julián Marías en su $\mathrm{H}^{\mathrm{a}}$ de la $\mathrm{f}^{\mathrm{a}}$, "este mundo del hombre griego es inteligible. Se puede comprender; y esta comprensión consiste en ver o contemplar esa realidad y decir lo que es: teoría, logos y ser son los tres términos decisivos del pensamiento helénico y se fundan en esa actitud primaria ante el mundo. La consecuencia de ello es que el mundo aparece como algo ordenado y sometido a ley; esta es la noción de cosmos".

Sin duda no es todo tan claro como esta línea de pensamiento nos puede dar a entender (Está presente también la visión dionisíaca), pero sí el punto de arranque de lo que será el pensamiento de occidente.

En este largo intento de comprensión de la realidad surgen dos maneras de afrontar los problemas, que recorrerán toda la historia del pensamiento: racionalismo y empirismo.

\footnotetext{
* Agradezco las sugerencias de los profesores M. Fartos Martínez y Antonio Ma Revilla.
} 
Pese a todas las diferencias que encontramos entre los miembros que agrupamos en una $\mathrm{u}$ otra de estas corrientes, podemos establecer ciertas notas definitorias de cada una de estas posturas. El empirismo afirma como núcleo de su naturaleza que todo conocimiento humano procede, en último término, de la experiencia sensible.

Por el contrario, el racionalismo acentúa la función de la razón como fuente de conocimiento, radicalmente diferente a la función de los sentidos, que, para unos no tienen una función válida, $y$, para otros, aunque afirmen la falta de fiabilidad de los sentidos, admiten la necesidad de la experiencia sensible para el conocimiento.

En el racionalismo se defiende que el conocimiento es a priori (antes de la experiencia o independientemente de la experiencia) y que este conocimiento no se refiere sólo a las tautologías, sino que, las proposiciones que usa expresan contenidos referidos a la realidad.

El apriorismo, a su vez, está vinculado al innatismo (se explique como se explique) y acepta que nuestra mente está dotada de ciertos esquemas o conceptos o, incluso, con ciertas verdades previas.

En este estudio hemos querido analizar si los a prioris kantianos pueden encontrar justificación en el momento actual, sobre todo, desde la biología del conocimiento y desde la metodología popperiana. Procedemos haciendo unas consideraciones históricas, para en un segundo momento referirnos a algunas teorías actuales que parecen justificar los a prioris incluyendo el punto de vista de la neurobiología. Concluiremos estableciendo ciertos resultados, derivados de las consideraciones anteriores.

\section{II.- Consideraciones históricas}

Si quisiéramos simplificar mucho las cosas, podríamos decir con Rorty ${ }^{1}$ que la filosofía antigua y medieval trataba acerca de las cosas, la filosofía del siglo XVII al XIX sobre las ideas, y la contemporánea sobre las palabras. No deja de ser una simplificación; pero, por lo que se refiere al tema que nos va a ocupar puede servirnos para comprender la evolución de los problemas y de las ideas relativos al conocimiento humano y a la relación entre el pensamiento y el objeto. Podríamos decir que la evolución ha sido: conocimiento de la realidad (esencia), análisis de las condiciones formales y necesarias del sujeto (transcendental) y análisis de las condiciones formales del lenguaje. Siempre se ha pretendido comprender y explicar cómo es posible el fenómeno del conocimiento humano. En este estudio pretendo sobrevolar aquellos

1. R.Rorty, La filosofía y el espejo de la naturaleza, ed. Cátedra. 
autores que considero más significativos sobre el asunto que nos ocupa refiriéndome también a la neurobiología y a las teorías cognitivas y del procedimiento de la información.

\section{1.- Platón}

Puesto que la revisión histórica no pretende ser exhaustiva, comenzamos con Platón. A Platón le interesa la verdad ontológica, verdad que podría identificarse con la lógica.

Nos referiremos al concepto de la anámnesis². Este tema lo estudia Platón, además de en el Menón (81b), que es el texto que nosotros vamos a considerar, en el Fedón ( 72 c y ss.), en el Fedro ( 249 b y ss.), y en el Filebo (34 a y ss.). Se encuentran también referencias a la anámnesis en Leyes (732 a y ss.) y en República (604 d).

Dejando al margen el asunto general del diálogo, nos detenemos sólo en la anámnesis. Una de las tesis que aquí se defienden es que el saber y la ciencia misma son recordar, son una reminiscencia. ¿Cómo se puede interpretar esto?

Una de las posibilidades de interpretación y, a la vez, más común, es la que vincula la anámnesis a la preexistencia del alma. Y, en efecto, Platón comienza la exposición de este problema $(81$ b) refiriéndose a Píndaro, a los poetas y a los sacerdotes:

"Sócrates :- Cosas verdaderas, a mi modo de ver, y bellas.

Menón: ¿Qué cosas? ¿Y quiénes son los que las decían?.

Sócrates: - Se trata de sacerdotes y sacerdotisas llenos de interés por dar razón de las funciones que desempeñan; se trata también de Píndaro y de gran número de otros poetas, todos los que son realmente divinos. $Y$ he aquí lo que ellos dicen: mira si su forma de hablar te parece exacta.

Dices, en efecto, que el alma del hombre es inmortal y que unas veces abandona la vida, que es lo que se llama morir, y otras veces entra de nuevo en ella, pero que nunca se destruye; y que, por este motivo, hay que llevar en esta vida, hasta el fin, una conducta tan santa como sea posible:

Así pues, el alma, inmortal y diversas veces renacida, al haber contemplado todas las cosas, tanto en la tierra como en el Hades, no puede menos que haberlo aprendido todo..."3.

2. Sigo la interpretación de E. Lledó, La memoria del logos, Taurus, Madrid, 1984. Para el fin que me propongo considero que no es necesario detenerse en todas las discusiones de los especialistas.

3. Platón, Menón, Obras Completas, Aguilar, Madrid, 1972, pág. 445- 446. 
Es evidente que aquí Platón se mueve en un transfondo mítico-religioso que puede constatarse también en los otros diálogos que cito al principio de este capítulo. Habría, por tanto, un primer nivel mítico ${ }^{4}$ junto con un segundo nivel de interpretación que es el que nosotros queremos señalar, y que es el que se refiere a la perspectiva racional de la anámnesis:

"Al ser homogénea toda la naturaleza y al haberlo aprendido todo el alma, nada impide que un solo recuerdo, que los hombres llaman saber, le haga encontrar de nuevo todo lo demás, si uno es valiente y tenaz en la búsqueda; porque la investigación y el saber no son en definitiva más que reminiscencias"5.

Podemos distinguir con Lledó ${ }^{6}$ diversos supuestos y tesis en este texto:

“1) Hay una íntima concatenación y dependencia en la naturaleza.

2) El alma ha tenido experiencia de todas las cosas.

3) Sobre la base de esta interdependencia de la naturaleza, el recuerdo de una cosa puede llevarnos lógicamente al conocimiento de otra.

4) Identificación del hecho de recordar algo con lo que suele llamarse aprendizaje: .

5) Apelación a un elemento personal, radicado en la esfera moral más que en la intelectual.

6) Como resumen, una identificación no sólo de aprender y recordar sino también de saber".

A su vez, es necesario, a nuestro juicio, partir de lo que Platón entiende por pensar y por conciencia, para desarrollar el segundo significado de la anámnesis al que ya nos hemos referido.

En el Teeteto (189 e ), al preguntarle éste a Sócrates a qué llama pensar, Sócrates responde:

"Para mi el pensar es una especie de discurso que desarrolla el alma en sí misma acerca de las cosas que examina... Así se me aparece el alma en el acto de pensar: esto y no otra cosa es el diálogo o las preguntas y respuestas que el alma se dirige a sí misma, unas veces afirmando y otras negando"7.

Así pues, pensar es diálogo del alma consigo misma. La conciencia tiene una estructura dialógica y en este diálogo se expresa la verdad. Elemento

4. P. Friedländer, Platon, Berlín, De Gruyter, 1954, pág. 347, n. 13, hace referencia al doble nivel mítico y racional de la "anámnesis". (Citado por E. Lledó, op. cit. pág. 125).

5. Platón, Menón, Aguilar, Madrid, 1972, pág. 446.

6. E. Lledó, op. cit. pág. 126 y ss.

7. Platón, Teeteto, O. C., Aguilar, Madrid, 1972, pág. 926. 
fundamental para el diálogo es el lenguaje ${ }^{8}$. A través del lenguaje se transciende la soledad de la conciencia. ¿Qué es, por tanto, en este contexto, la anámnesis?

Al citar anteriormente el texto $81 b$, especificábamos una serie de tesis que se expresan en él. Se habla de la homogeneidad de la naturaleza, de la "coherencia sistemática de la naturaleza, de la que el hombre es elemento esencial", necesaria para que pueda darse el conocimiento. "Parece aludir a la posibilidad de relación cognoscitiva sobre una base empírica imprescindible entre el hombre y su mundo".

Esta homogeneidad, a nuestro juicio, podría interpretarse de la siguiente manera: Tenemos el mundo de las Formas que es el mundo de la auténtica realidad (nivel ontológico); Su jerarquía real coincide con su estructuración lógica; Este mundo es el que copia el mundo sensible de la forma menos imperfecta posible. De ahí que se de la homogeneidad de la naturaleza. El alma, de naturaleza afín a las ideas, posee una estructura lógica que le permite representarse, a través del recuerdo, el mundo de las formas. De ahí también la homogeneidad entre el alma y la naturaleza.

La otra afirmación se refiere al proceso asociativo: ... "Nada impide que un solo recuerdo, que los hombres llaman saber, le haga encontrar de nuevo todos los demás".... ${ }^{10}$.

Se trata aquí, por una parte, de la relación entre el recuerdo que está en nosotros y un posible conocimiento futuro. En la anámnesis se supera lo ya sabido. Y, por otra, se proyecta hacia el futuro. El texto al que me estoy refiriendo concluye: "porque la investigación y el saber no son en definitiva más que reminiscencias"11. Al decir de Lledó, quedaría superado claramente el carácter mítico del que parte la anámnesis: se define como aprendizaje e investigación.

El otro pasaje del Menón en el que queremos detenernos es el del esclavo $^{12}$. Lo que pretende con este experimento Platón se lo plantea Sócrates a

8. Sigo utilizando la obra citada de E. Lledó, pág. 120 y ss.

9. E. Lledó, op. cit., pág. 127. La expresión de Aristóteles es que "el alma es, en cierto modo, todas las cosas". (De An. III, 431 b 21). En la epistemología evolucionista se dirá que aplicamos nuestras leyes al mundo porque antes (a lo largo de la evolución) éstas han sido transcritas en nuestro aparato cognoscitivo). Conviene a este respecto también tener en cuenta la idea que ya puede detectarse en Parménides y en Heráclito del replegarse del hombre en un esfuerzo sobrehumano a lo profundo de la la naturaleza (somos naturaleza), de forma que, entre ella y nosotros existe isonomía (Cfr.: al respecto, M. Fartos, Historia de la filosofia y de la ciencia, Universidad de Valladolid, 1992).

10. Platón, Menón, O. C., pág. 446.

11. Ibidem.

12. Platón, Menón, O. C., pág 446 y ss. 
Menón:" Examina si parece recordar o si parece aprender de mi"13. El lenguaje es el primer requisito para que se verifique la anámnesis, para que el esclavo traiga a la conciencia el conocimiento (recuerdo): “ ¿es griego y habla griego?"14.

Pero quisieramos insistir todavía en otros dos requisitos que se presuponen: lo que realmente hace Sócrates a través de sus preguntas es situar al esclavo, primero, en la órbita de la lengua conocida (común) y, en segundo lugar, presuponer que mediante ella, se penetra en una lógica universal de la que el esclavo participa estructuralmente, lo que a su vez le permite conocer las formas impresas en su alma. Con ello se alcanza el nivel ontológico. "Sabrá, pues, sin haber tenido maestro, gracias a simples preguntas, habiendo vuelto a encontrar en sí mismo por sí mismo su ciencia"15.

Vemos, pues, cómo en Platón el a priori presentaría un aspecto ontológico y otro lógico, que a su vez, serían localizados en el alma humana (racional), como copias del auténtico mundo de las esencias. El mundo sensible y el lenguaje vienen a ser los instrumentos que despiertan la anámnesis.

\section{2.- El a priori de Santo Tomás ${ }^{16}$}

Si bien Santo Tomás pretende seguir el modelo aristotélico, es bien sabido que en las cuestiones más candentes no siempre supera el sistema platónico como en lo referente a la teoría del conocimiento.

En la obra de Tomás de Aquino se advierte una clara evolución que pasa, en lo referente al conocimiento, de la explicación aristotélica a adoptar en su época madura fórmulas neoplatónicas.

La pregunta que se plantea es ¿cómo es posible el conocimiento de la realidad, de la esencia?.

Siguiendo las líneas aristotélica, el entendimiento agente inmanente en el hombre ilumina la imagen sensible y mediante el proceso de abstracción obtiene el universal del objeto que se expresa mediante el concepto.

Sin embargo, en la fase madura de su pensamiento recurre a la iluminación por parte de un Intelecto superior. Veamos esta evolución.

Santo Tomás se refiere al conocimiento en varias obras. Algunas de estas son las siguientes: Comentario a las sentencias, In Johannem, $1^{a}$ Parte de la Summa theologica y en la Quaestio de veritate, además de otros pasajes.

13. Ibidem.

14. Ibidem.

15. Ibidem.

16. Sigo en este apartado la exposición de L. Cencillo, Conocimiento, ed. Syntagma, Madrid, 1968, pág. $81-98$. 
Elemento clave de este análisis es el "Verbum mentis", que en un principio no se distingue realmente de la intelección y que al final se transforma en algo independiente: "porque el verbo se comprende como proviniendo de una acción inteligible" (I q. 28, a 4 ad 1 ). Esta separación es la que parece impedir el contacto directo del entendimiento con la esencia.

Ahora bien, la cuestión es esta: ¿Puede el entendimiento humano, por sí mismo, captar la esencia de un objeto? ¿O necesitamos la acción externa de algún tipo de inteligencia?..Téngase en cuenta además, que, siguiendo a Aristóteles, Santo Tomás afirma la necesidad de poner en el alma misma " alguna virtud (capacidad) participada por el mismo entendimiento superior, mediante la cual el alma humana realice en acto los inteligibles" (q. 16, a. 7 c ). Esta necesidad se sigue del hecho de que cada naturaleza al tener un fin propio, debe estar dotada también de los medios propios e intrínsecos para conseguirlo.

Estas capacidades, sin embargo, "se derivan de agentes universales" (q. 16, a. 7 c ). ¿Dónde se localizan? El alma participa su capacidad intelectiva del Intelecto divino: “ Puesto que sólo el entendimiento divino es eterno, en él sólo encuentra la verdad su eternidad” (Ibidem).

Pero, tampoco soluciona mucho santo Tomás con esto: $\mathrm{O}$ bien la participación se hace mediante el propio entendimiento del hombre por su propia naturaleza, o bien se trata de un influjo de Dios en cada intelección. En el primer caso, no se necesitaría otra explicación que el propio entendimiento. En el segundo caso, no se ve la necesidad de un agente externo al entendimiento, si ya éste podría explicar la intelección.

Para explicar la influencia del intelecto divino en el entendimiento humano santo Tomás recurre a dos metáforas: el espejo y la luz. El alma para conocer se sirve (q. 16, a 6 ad 1) como principio de conocimiento de la verdad absolutamente primera, que es el contenido de la mente divina y que se convierte en principio lógico del conocimiento natural "en cuanto que se encuentra en ella como en un espejo, como los primeros inteligibles".

No parece válida esta metáfora en cuanto que el espejo sólo refleja y nos llevaría a consecuencias no deseadas por santo Tomás.

La metáfora de la luz se expresa sintéticamente de la siguiente manera: "El juicio de la mente humana se realiza como la fuerza de la luz intelectual" (II, II, q. 173, a. 2 c).

Santo Tomás se plantea la fundamentación de los principios lógicos y nuevamente recurre al esquema neoplatónico. El "intellectus principiorum " fundaría toda certeza en las razones eternas: 
"Es preciso decir que el alma humana conoce todas las cosas en relación a las razones eternas, mediante la participación de las cuales conocemos todas las cosas"... ( q. 84, a. 5 c ).

No es que la mente capte directamente las razones eternas; pero influyen en ella como "medium quo" o " sub quo".

Ahora bien, volvemos al dilema si queremos precisar qué sea esto: o el entendimiento humano posee estas razones en sí mismo por naturaleza o por un acto libre de Dios. Si lo primero, nos sobra la "iluminación" ; si lo segundo, caeríamos en el voluntarismo, lo que no admitiría santo Tomás. No parece suficiente la metáfora de la luz.

Santo Tomás afirma que el entendimiento humano posee los principios por su propia naturaleza:

"En la razón especulativa existen ciertas cosas naturalmente conocidas, de las que existe intelección" (II, II, q. 49, a. 2 c y 47, a. 6 c. ).

Además, las especies inteligibles nos llegan también de las cosas materiales, a través de los sentidos, para que podamos conocerlas (I, q. 84, a 5 c . ). El entendimiento en acto es informado por la misma forma del objeto y el conjunto de estas formas constituye el mundo inteligible, como contenido de la ciencia (q. 85, a. 1 ad 4$)^{17}$.

Si esto fuese así, no se precisaría ningún a priori lógico, sino solamente un proceso sicológico de desmaterialización y la ciencia sería conocimiento de la realidad esencial:

"Así pues, se debe afirmar que la especie inteligible se posee para comprender como aquello por lo que el entendimiento comprende. Es manifiesto (... ) que la forma según la cual proviene la acción que permanece en el agente es la semejanza del objeto (... ) y que la semejanza de la cosa comprendida, que es la especie inteligible es la forma según la cual el entendimiento comprende"18.

¿A qué viene entonces la necesidad de que para un conocimiento absoluto precisemos de las razones eternas? ¿Qué papel desempeña la iluminación del entendimiento humano en el "intelecto de los principios"?. Santo Tomás no lo aclara.

Sea que se trate de una intuición de los primeros principios del ser, sea que se trate de la desmaterialización, ninguna de estas dos posiciones parecen requerir la apelación a las "verdades eternas".

17. Cfr.: Cencillo, op. cit., pág. 92.

18. Lo contrario sería la posición de Ockam y la del mismo Kant, a saber, que lo que conocemos es lo que está en el alma y no en las cosas fuera del alma. Cfr.: q. 85, a. 2c y ad 1. 
La tercera posibilidad que analiza el profesor Cencillo ${ }^{19}$ nos parece también la más apropiada: se trataría de una reelaboración de las especies recibidas de los objetos materiales.

Con lo cual se pretende, por una parte, conocer la estructura real del mundo, pero no simplemente, sino que, para conseguir el valor absoluto de todo conocimiento, se precisa, por otra, la aplicación de modelos que la mente constituye a partir de la estructura real y de acuerdo con unos principios a priori (lógicos) que dimanan de la propia mente. $\mathrm{Y}$ aquí es donde santo Tomás recurre a las razones eternas participadas por el entendimiento humano del Intelecto divino como garantía que salve la posible relatividad del conocimiento humano.

De este breve análisis podemos resumir la posición de santo Tomás. Nos encontramos con un a priori lógico-ontológico que se especifica en un triple movimiento: Un Intelecto superior con las razones eternas por contenido, un entendimiento agente inmanente al espíritu humano en su doble función de desmaterializar las formas sensorialmente aprehendidas y de participar por el intellectus principiorum de las razones eternas, y, principalmente, de parte del objeto, el eidos inteligible en potencia.

\section{3.- G. de Ockam ${ }^{20}$}

Ya con la teoría de la abstracción de Scoto había comenzado el distanciamiento de lo que podría entenderse como la intuición directa de la esencia. Tal distanciamiento culminará en Ockam y posteriormente en el empirismo y en Leibniz y en Kant.

Según Ockam nuestro conocimiento parte de la intuición intelectual. Nuestro entendimiento está en relación directa con los objetos sensibles y capta su existencia actual:

"Cognitio intuitiva est illa per quam cognosco rem esse, quando est, et non esse, quando non est" (II Sent. q. 15 E.).

Existe también un conocimiento abstractivo que capta el objeto como objeto sin tener en cuenta si existe o no. Lo que diferencia ambos tipos de

19. L. Cencillo, op, cit., pág. 96.

20. Para este breve resumen de Ockam puede consultarse: T. de Andrés, Actividad del entendimiento y formación del universal en la psicología de Guillermo de Ockham, "Miscella Comillas", 1967 (47-48), pág. 267-297. -La significación "representativa" en Guillermo de Ockham, en "Pensamiento", 24 (1968), pág. 375-381. -El nominalismo de Guillermo de Ockham como filosofia del lenguaje, Gredos, Madrid, 1969.

-A. Ghisalberti, Guglielmo di Ockham, Vita e pensiero, Milano, 1980. No entro en las discusiones técnicas. En estos autores existe una amplia bibliografía. 
conocimiento es que el conocimiento intuitivo enuncia juicios sobre lo que existe (contingentes), mientras que el conocimiento abstractivo no ${ }^{21}$.

El conocimiento intuitivo puede, a su vez, ser perfecto o imperfecto; en el primer caso hablamos de algo que existe actualmente; en el segundo, se trata de proposiciones referidas al pasado (este segundo caso se asemeja al conocimiento abstractivo).

El conocimiento abstractivo puede ser también de dos tipos: uno, el que acaba de ser citado; otro, el conocimiento conceptual o conocimiento del universal ${ }^{22}$.

Nos importa analizar el origen y la naturaleza de los conceptos universales, en este segundo sentido.

Concepto es "aquello que se puede predicar de la realidad"23. Sus características se relacionan con su función y con su naturaleza. Considerando que el concepto es una realidad individual, su función consiste en que se predica de varias cosas.

La diferencia de la concepción de Ockham respecto a la de santo Tomás radica fundamentalmente, en que a diferencia de éste, que admite el fundamento del universal en la esencia común, para Ockham lo que existe es el individuo, y que la realidad individual como tal, es inteligible. Todo esto significa que el principio de individuación carece de vigencia; pero a la vez, que, detrás del universal, no existe ningún resto metafísico y que, por tanto, lo único que importa de ellos, es su origen en nuestra mente y su propia naturaleza. El universal sólo existe en nuestro pensamiento.

Ockham distingue dos tipos de universales: los orales y escritos como signos convencionales, y los conceptos propiamente dichos, como signos naturales ${ }^{24}$. Ambos son signos: están en el discurso en lugar de los objetos(suppositio), si bien "suponen" o convencionalmente (los primeros) o naturalmente (los segundos). Aquí nos importan los segundos.

21. "Non quod aliquid cognoscatur per notitiam intuitivam quod non cognoscitur per notitiam abstractivam, sed idem totaliter et sub omni eadem ratione cognoscitur per utramque notitiam. Sed distinguuntur per istum modum: quia notitia intuitiva rei est talis notitia virtute cuius potest sciri utrum res sit vel non, ita quod si res sit, statim intellectus judicat eam esse et evidenter cognoscit eam esse, nisi forte impediatur propter imperfectionem illius notitiae... Notitiam autem abstractiva est illa virtute cuius de re contingente non potest sciri evidenter utrum sit vel non sit. Et per istum modum notitia abstractiva abstrahit ab exsistentia et non exsistentia, quia nec per ipsam potest evidenter sciri de re exsistente quod exsistit, nec de non exsistente quod non exsistit, per oppositum ad notitiam intuitivam". (In I Sent. , Prol. 1).

22. G. de Ockham, In I Sent. , Prol. 1.

23. G. de Ockham, Summa Logicae, I, 14, pág. 44-45.

24. Ibidem. 
En relación a la naturaleza del universal Ockham expone tres concepciones diversas 25 :

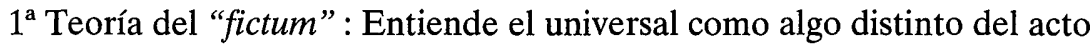
intelectual, dotado de una existencia ideal que sería el "esse obietivum": representación mental ["fictum"] o imagen mental del objeto. La semejanza entre la imagen y el objeto justifica la "suposición".

$2^{a}$ Teoría de la "Qualitas mentis". La teoría del "fictum" era criticada por W. Chatton, crítica que afecta cada vez más a Ockham, hasta llevarlo a abandonar la posición anterior sustituyéndola por la teoría que considera que el concepto en cuanto a su naturaleza es "una cualidad de la mente dotada de un "esse subietivum".

$3^{\text {a }}$ Teoría de la "intellectio ipsamet": Sin embargo, la teoría que acepta definitivamente es la que identifica el concepto con el propio acto de conocer: el concepto es el signo natural del objeto individual (No hay esencias, no hay individuación; y todo ello para salvaguardar la omnipotencia divina).

La teoría del concepto como signo es estudiada sobre todo por T. de Andrés en la obra citada, distinguiendo dos niveles: uno, significativo-representativo (imagen-vestigio) y otro, significativo-lingüístico, que procura una intelección primaria.

Por lo que se refiere al primer caso, el signo tiene la capacidad de significar un objeto en cuanto que hace surgir en la mente el recuerdo de lo que está representado en la mente o de lo que ha dejado el vestigio. Es recuerdo de lo que antes se había conocido.

La interpretación significativo-lingüística la resume de Andrés de la siguiente manera.(pág. 173) :

"En virtud de aquella preordenación estructural de nuestra facultad cognoscitiva a abordar significativamente la realidad exterior, esta facultad reacciona espontáneamente frente a la presencia activa de la realidad exterior, realizando el acto de conocer, la "intellectio ipsamet" que es (en cuanto reacción espontánea) un signo natural lingüístico, capaz de ser envío a muchas, e incluso a infinitas cosas; Pero "pro statu isto" (como diría Ockham) el campo de objetos significados queda limitado por el hecho de la mayor o menor semejanza meramente fáctica y no basada en la presencia, siquiera potencial, de una "natura". 


\section{4.- El a priori cartesiano ${ }^{26}$}

En relación a Descartes nos importa destacar aquellas novedades que realmente nos permiten hablar de filosofía moderna sobre todo en el ámbito de la teoría del conocimiento.

Podemos decir, en general, que el pensamiento se orienta no a buscar el fundamento ontológico de la realidad, sino más bien, un método que posibilite la deducción matemática a partir del a priori puramente lógico.

El a priori de Descartes es complejo, pero, podemos sintetizarlo en una especie de triple juego: el Cogito, las ideas innatas y Dios, sumamente veraz, que garantiza nuestras ideas acerca del mundo.

Ya no existe aquella forma del objeto, sino que, todo lo que podemos conocer ha de ser derivado de nuestras ideas innatas de un modo lógico-formal.

Descartes parte de la duda metódica: es preciso rechazar todo aquello sobre lo que tengamos alguna duda, tanto respecto a Dios, como a la existencia de los cuerpos, como sobre nosotros mismos. Pero, mientras hacemos este ejercicio, se nos presenta la verdad indubitable de nuestro yo: no podemos dudar de que existimos mientras dudamos ("Repugnat enim, ut putemus id quod cogitat, eo ipso tempore quo cogitat, non existere"). El ego cogito, ergo sum se convierte en la verdad primera e indubitable y en criterio de cualquiera otra verdad.

La originalidad cartesiana reside, no tanto en la formulación (puesto que existen precedentes históricos, (G. Fraile destaca 8. ), sino en "el carácter problemático que en virtud del cogito pasa a asumir toda realidad distinta del yo"27.

El pensamiento piensa ideas. $\mathrm{Y}$ entre estas, las hay de tres tipos: innatas ("me parecen nacidas conmigo"); adventicias, ("extrañas y procedentes de fuera"); y facticias, ("hechas o inventadas por mi mismo").

Nos importa la doctrina de las ideas innatas. Aunque estas se interpretaron como si tuviesen una existencia actual, la verdad es que Descartes se refería a la facultad innata de formar esas ideas(por tanto, virtualmente innatas): tales como substancia-mente, Infinito-Dios; extensión, duración y número. Sobre esta aclaración conviene tener en cuenta el texto siguiente:

"La doctrina del artículo doce no parece distinguirse de lo que yo opino en relación con este problema sino en cuestión de palabras. Cuando éste

26. R. Descartes, Oeuvres de Descartes. Publiées par Ch. Adan et P. Tannery, Paris, Libraire Philosophique, J. Vrin, 1969, Discours de la mèthode, VI. Meditationes de prima Philosophia, VII. Principia Philosophiae, VIII-I. Metitations, IX-I. Principes, IX-I.

27. N. Abbagnano. Historia de la Filosofía, 3 V, Montaner y Simón, Barcelona, 1964. 
afirma que la mente no necesita ideas, o nociones, o axiomas innatos y, al mismo tiempo, atribuye a ésta la facultad de pensar (esto es, una facultad natural innata), está defendiendo una doctrina igual a la defendida por mi, aunque parece negarlo con sus palabras. En realidad nunca he escrito o pensado que la mente precise de ideas innatas, que fuesen algo diverso de su propia facultad de pensar. Más bien, advirtiendo la existencia en mi de algunos pensamientos que no procedían de los objetos externos ni de la determinación de mi voluntad sino de la facultad de pensar que poseo, con el fin de distinguir las ideas o nociones que son las formas de estos actos de pensar de aquellas otras que son adventicias o construidas, he decidido llamar a las primeras innatas. Uso este término en el mismo sentido que cuando afirmamos que la generosidad es innata en algunas familias y que en otras lo son algunas enfermedades como la gota o el cálculo, pero no en el sentido de que los hijos de esas familias padezcan esas enfermedades desde el vientre de sus madres, sino en el sentido de que nacen con cierta disposición o facultad para adquirirlas" 28 .

A partir de la idea de Infinito se demuestra su existencia mediante los argumentos ideológico, cosmológico y ontológico.

Con la demostración de la existencia de Dios, infinitamente bueno y veraz, se abre el camino para la demostración de la existencia del mundo como extensión y movimiento.

Así pues, el apriori cartesiano del conocimiento se mueve en el triple juego.

$\mathrm{El}$ cogito como experiencia primaria y original; las ideas innatas (razones eternas de santo Tomás, juntamente con su intellectus principiorum); y, la veracidad de Dios.

Ningún contenido es recabado del objeto, sino que todo procede de las ideas: el orden de la razón será el orden de la realidad.

\section{5.- Leibniz y las ideas innatas ${ }^{29}$}

Un autor clásico del innatismo es Leibniz que desarrolla su apriorismo lógico frente a la concepción sicogenética de Locke.

Nuestro autor pretende averiguar "si, como piensan Aristóteles y el autor del tratado, el alma está en sí y por sí absolutamente vacía como un

28. Descartes, Obsevaciones, en Explicación de la mente humana o del alma racional, que incluye la exposición de lo que es y de lo que puede ser; en Cuadernos Teorema, 1981, pág. 2021. Cfr. : M. Fartos Martínez, op. cit. , pág.307.

29. Utilizo la obra de Leibniz, Nuevo tratado sobre el entendimiento humano, Aguilar, Buenos Aires, 1970. 
papel en el cual no se ha escrito nada (tabula rasa), y de si todo lo que en ella se graba procede de los sentidos y de la experiencia, o si, por el contrario, el alma contiene originariamente las razones iniciales de diferentes conceptos y doctrinas, que sólo con ocasión de los objetos exteriores se despiertan en ella"... ${ }^{30}$.

De esta primera investigación nace otra cuestión: "la de si todas las verdades dependen de la experiencia, es decir, de la inducción o de los ejemplos, o si entre ellas hay algunas de tal naturaleza que es necesario señalarles otro origen"31.

Para Leibniz, los sentidos nos son necesarios para el conocimiento real, pero no suficientes para justificar la generalidad y universalidad de la verdad: "las verdades necesarias... deben apoyarse en principios cuya demostración no dependen de los ejemplos, ni por consiguiente del testimonio de los sentidos, si bien es verdad que sin los sentidos nunca llegaríamos al conocimiento de estas verdades" 32 .

Estos principios en los cuales se sustentan los principios de las matemáticas, de la lógica, de la metafísica y de la moral, son los que se llaman principios innatos.

En relación a Locke, cuando acepta que hay ideas que provienen de la reflexión, Leibniz se pregunta:"¿Se podrá negar luego que hay en nuestro espíritu mucho de innato puesto que, por decirlo así, somos innatos a nosotros mismos, y que el ser, la unidad, la sustancia, la duración, el cambio, la actividad, la representación, el gusto y otros mil objetos de nuestro intelecto son en cierto modo innatos?" 33 .

Recurre Leibniz a la metáfora del mármol veteado conteniendo la figura de Hércules antes que otra, independientemente del esfuerzo que se requiere para descubrir y destacar esas vetas. "En este sentido, las ideas y las verdades son innatas en nosotros como inclinaciones, disposiciones, capacidades o facultades naturales; pero no como actividades o funciones, si bien dichas facultades van siempre acompañadas de ciertas correspondientes actividades imperceptibles" 34 .

Leibniz establece la distinción entre percepción y apercepción en relación a la actividad constante de toda sustancia y, por tanto, del alma. Habla

30. Leibniz, op. cit. , pág.29. Ver Aristóteles, Del alma, III, 4, 429 a 15, 429 b 30.

31. Leibniz, op. cit. , pág. 30.

32. Leibniz, op. cit. , pág. 31.

33. Leibniz, op. cit. , pág. 34.

34. Cfr.: Leibniz, op. cit. , pág. 36-37. Según B. Russell, "Leibniz, en realidad, tomaba por una sola cuatro cosas aparentemente diferentes, a saber, 1) la percepción inconsciente, 2) la percepción confusa, 3) la percepción infinitesimal y 4) la disposición psíquica", Exposición crítica de la filosofía de Leibniz, siglo veinte, Buenos Aires, 1977, pág. 184. 
de una multitud de percepciones que no van acompañadas de apercepción ni reflexión, sino que representan variaciones del alma o demasiado débiles y numerosas, o demasiado uniformes para hacernos conscientes de ellas, pero que unidas producen su efecto y se dejan sentir, como sucede con el ruido de las olas. No percibimos claramente el ruido de cada gota de agua, sino del conjunto, pero no percibiríamos el todo sin la percepción imperceptible de cada gota ${ }^{35}$ : "Y hasta puede decirse que en fuerza de estas pequeñas percepciones el presente está preñado de porvenir y repleto del pasado, que todo se relaciona..., y que una mirada tan penetrante como la de Dios podría leer en la más humilde sustancia la historia entera del universo"36.

En el libro I comienza el diálogo entre Filaletes, (Locke) y Teófilo, (Leibniz).

Leibniz tiene que responder a la posición de Filaletes: "No hay ni ideas ni principios innatos. Para refutar semejante error basta, como luego veremos, demostrar que no se necesitan y que los hombres pueden adquirir todos sus conocimientos sin necesidad del concurso de ninguna impresión innata" 37 .

Teófilo comienza haciendo una declaración de principios: Cree en la idea innata de Dios y cree también en otras ideas innatas; incluso cree "que todos los pensamientos y actividades de nuestra alma provienen de su propio fondo y no de las impresiones sensibles"38.

A partir de aquí comienza la "exposición-discusión" entre el innatismo y el empirismo ${ }^{39}$.

Aunque en el mismo prólogo de Leibniz se encuentran las tesis fundamentales, vamos a referirnos brevemente también a este capítulo primero para destacar los puntos básicos que Leibniz establece. No se trata de justifi-

35. Cfr.: Leibniz, op. cit. , pág. 36-37. Según B. Russell, "Leibniz, en realidad, tomaba por una sola cuatro cosas aparentemente diferentes, a saber, 1) la percepción inconsciente, 2) la percepción confusa, 3) la percepción infinitesimal y 4) la disposición psíquica", Exposición crítica de la filosofía de Leibniz, siglo veinte, Buenos Aires, 1977, pág. 184.

36. Leibniz, op. cit. , pág. 38-39.

37. Leibniz, op. cit. , pág. 73.

38. Ibidem.

39. En la teoría de las ideas innatas Leibniz presupone, como es obvio, sus concepciones metafísicas; en especial, me refiero a su concepción de las mónadas y a la armonía preestablecida: cada mónada es una representación, un punto de vista sobre el universo. La percepción de las mónadas es de la totalidad del mundo: en ellas está todo, si bien, en unas, de forma más confusa, y, en otras de forma más clara, pero dentro de lo que es la armonía preestablecida. Esto significa que en el fondo hay acuerdo perfecto, aunque éste no sea claro ni para Teófilo ni para Filaletes. Lo sería, sin embargo, para quien pudiese penetrar en esa armonía profunda, es decir, Dios. Cfr.: La introducción de J. Echevarría Ezponda a Los Nuevos ensayos... ed. Nacional, Madrid, 1983. 
car los principios innatos por la aceptación unánime de los mismos, pero esta aceptación es ya un indicio de su existencia. Incluso, si no fueran conocidos "serían innatos, porque los reconocemos y acatamos en cuanto los formulamos" 40 . Lo cual no sería contradictorio (un conocimiento no conocido) como puede verse con recuerdos almacenados en la memoria pero no presentes a la conciencia de modo actual. De forma virtual e innata existen en nuestra alma toda la aritmética y la geometría y puede actualizarse a través de la atención y el orden sin necesidad de nociones adquiridas por la experiencia y la tradición ${ }^{41}$.

Existen dos clase de verdades: verdades necesarias o de razón y verdades de hecho; pero la razón es la fuente de las primeras y sólo a través de la razón se justifica la necesidad de las mismas ${ }^{42}$.

Que el entendimiento sea la fuente de estas verdades no significa sólo la capacidad de comprenderlas, "sino de una disposición, de una aptitud, de una preformación que determina nuestra alma y hace que esta pueda extraerlas"43. (Cfr.: el ejemplo del mármol veteado).

E insiste Leibniz en su tesis: "las ideas que proceden de los sentidos son confusas, y lo mismo puede decirse, por lo menos en parte, de las verdades que de ellas dependen; mientras que las ideas intelectuales y las verdades de ellas dependientes son precisas y claras, y ni unas ni otras deben su origen a los sentidos, aunque es cierto que sin los sentidos no pensaríamos nunca en ellas"44.

A la objeción que hace Filaletes en relación a la mayor dificultad de conocer las ideas abstractas y generales que las especiales, Leibniz, después de reconocer este hecho, responde que efectivamente vamos de lo más sencillo a lo más complejo. Pero que "los principios generales penetran en nuestro entendimiento y forman, por decirlo así, su constitución. Son, pues, necesarios, como lo son los músculos y los tendones, aunque no nos demos cuenta de ello. El espíritu se apoya en cada momento en estos principios"45.

Y no se trata de oponer la naturaleza de las cosas al espíritu. Ambos concurren en el conocimiento. Pero por lo que se refiere a la luz natural "supone un conocimiento claro, y a menudo, la consideración de la naturale-

40. Leibniz, op. cit. , pág. 77.

41. Cfr.: Leibniz, op. cit. , pág. 78-79; La referencia es al esclavo del Menón de Platón. Véase nuestro apartado 2. 1.

42. Cfr.:Leibniz, op. cit. , pág. 83. Sobre la distinción de las dos clases de verdades, Cfr.: Leibniz, Escritos en torno a la libertad, el azar y el destino, Tecnos, Madrid, 1990, pág. 6 y ss.

43. Leibniz, op. cit. , pág. 84.

44. Leibniz, op. cit. , pág. 85.

45. Leibniz, op. cit. , pág. 89-90. 
za de las cosas no es más que la consideración de la naturaleza de nuestro espíritu y de aquellas ideas innatas que no se necesita buscar en el exte. rior" 46 .

Por otra parte, "los principios innatos sólo aparecen cuando la atención se fija en ellos... Sólo se adquieren a costa de noble esfuerzo" ${ }^{47}$.

Una vez especificado el innatismo de Leibniz queremos precisar el tema del a priori. El planteamiento de Leibniz consiste en aceptar los elementos lógicos y la demostración adquirirá una certeza indubitable. Importa la rectitud formal de la lógica.

No se trata, por tanto, ya de un a priori ontológico, ni solamente de un método, sino de un "proceso continuado de conquista mediante la verificación de sus consecuencias"48.

Esto nos lleva a constatar que el a priori de Leibniz, a priori lógico se especifica mediante el principio de no contradicción (para los elementos abstractos) y el de razón suficiente (para las realidades físicas), el cual incluye, a su vez, el de continuidad o precontinencia del efecto en la causa ${ }^{49}$.

Pero, si partimos de la conciencia y de la conciencia cerrada, que lleva en sí todas las representaciones, ¿quién nos garantiza la veracidad real de estas representaciones? ¿Se da adecuación o correspondencia entre la representación y el mundo?. Para Leibniz este problema se resuelve por el procedimiento lógicamente espúreo de la armonía preestablecida ${ }^{50}$.

\section{6.- El a priori kantiano}

Kant representa un hito importantísimo en el problema del conocimiento, quien recogiendo ciertos elementos anteriores, va a elaborarlos, dentro del contexto de la ilustración, con nuevas y originales aportaciones.

Nosotros nos vamos a referir básicamente a la Crítica de la razón pura, si bien consideramos importante aludir a los resultados anteriores obtenidos por Kant, en relación a los problemas planteados desde la ciencia y la filosofía sobre los que Kant va a establecer su sistema innovador.

De cuanto llevamos dicho en los apartados anteriores, podemos advertir ciertas evoluciones en la relación entre el pensamiento y el ser y en la explicación de esta captación. Tal vez los hechos más llamativos pudiesen ser: la búsqueda en y desde la conciencia del posible conocimiento de las cosas;

46. Leibniz, op. cit. , pág. 90-91.

47. Leibniz, op. cit. , pág. 95.

48. L. Cencillo, op. cit., pág.121.

49. Véase La monadología, párrafos 31-32-33.

50. Cfr.: nuestra nota 39. 
búsqueda del origen (en Kant, transcendental) del conocimiento; y la consideración del saber científico como modelo del saber (en el racionalismo, la matemática, la física de Boyle en Locke y la física-matemática en Kant).

Hemos aludido anteriormente a la polémica entre Locke y Leibniz. Se discute el concepto de alma y en la época de Rousseau asistimos a la reivindicación del concepto que tiene Leibniz frente a la sicología de Locke.

En el fondo se trata de defender la autonomía del espíritu (contra el asociacionismo) y la libre creación del mismo. Se invoca la fuerza poética como expresión de la potencia fundamental del alma y de sus leyes y juicios, en cuya actividad juega un papel significativo la voluntad.

Uno de los sicólogos de la época que insistió en el desarrollo de este concepto fue Tetens ${ }^{51}$ (si bien sufrió una evolución importante en su obra desde el asociacionismo hasta el activismo de la conciencia). Tanto en el arte como en la ciencia existe una síntesis creadora que no se reduce a la pasiva asociación de sensaciones, ni a la simple observación inductiva de los hechos. Se parte de las sensaciones, pero "a ellas viene a añadirse un razonamiento, una actividad interior y autónoma del entendimiento... Estos pensamientos generales son verdaderos pensamientos, anteriores a toda experiencia"... ${ }^{52}$.

Y resaltando el papel activo y constructivo de la conciencia, nos referimos al texto siguiente: ... "Pero la geometría, la óptica, la astronomía, estas obras del espíritu humano, pruebas irrefutables de su grandeza, no cabe duda de que son conocimientos reales e invulnerables. Pues bien, ¿A qué reglas fundamentales se atiene la razón humana para construir estos inmensos edificios?"...53.

Con este texto se toca ya el problema transcendental de la conciencia.

La filosofía kantiana se entiende en relación a la ciencia de la naturaleza y como búsqueda de los fundamentos de la misma. Queremos reducir la existencia como un hecho a aquel entramado conceptual que nos permita conocer su estructura (Newton lo ha hecho en física y Kant va a realizarlo en la filosofía).

Ya Kant, en el Único fundamento posible para la demostración de la existencia de Dios, había descubierto, como postulado, que había que elevarse sobre los hechos, tanto del pensamiento como de la realidad hacia la condición que posibilita ambos. Entre los juicios analíticos (a priori) y los sintéticos (a posteriori) es necesario encontrar los juicios sintéticos a priori.

51. N. Tetens, Ensayos filosóficos sobre la naturaleza humana, Riga, 1777, 2 vol. Cfr.: E. Cassirer, El problema del conocimiento en la filosofia y en la ciencia modernas, F. C. E., México, libro cuarto, 1956, pág.520 y ss.

52. N. Tetens, op. cit. ,I, pág. 320 y ss. pág

53. N. Tetens, op. cit. ,I, pág. 427 y ss. 
Y volvemos al problema fundamental:

“¿Cómo cobran los juicios empíricos y sintéticos un carácter general? ¿No poseemos, junto a los principios formales de los juicios racionales, otros principios formales para los juicios sintéticos y empíricos? ¿No son los mismos los principios formales de la relación real que los de la relación lógica?"54.

En los Sueños de un visionario ${ }^{55}$ se encuentra el problema de la metafísica como la teoría de la estructura y de los límites de la razón humana.

Pero pasemos directamente a la Crítica de la razón pura ${ }^{56}$, para establecer las líneas maestras del a priori kantiano.

El planteamiento del problema queda claro en la Introducción. Una vez establecido que todo nuestro conocimiento comienza con la experiencia (B. 1), pero que no todo él procede de la experiencia, se trata de saber ¿por qué razón son válidas la matemática y la física (juicios sintéticos a priori) y si puede ser válida la metafísica como ciencia?

Si bien deseamos centrarnos en la Analítica, haremos también una breve referencia a la Estética.

Nuestra forma de referirnos a los objetos es la intuición que tiene lugar cuando nos es dado el objeto afectando de alguna forma a nuestro psiquismo:

"La capacidad (receptividad) de recibir representaciones, al ser afectados por los objetos, se llama sensibilidad. Los objetos nos vienen, pues, dados mediante la sensibilidad y ella es la única que nos suministra las intuiciones "57.

Posteriormente, los objetos serán pensados por el entendimiento, del que dependen los conceptos. Precisamente la Estética es "la ciencia de todos los principios de la sensibilidad a priori" (B.36), aislando de ella la labor del entendimiento, por una parte, y por otra, separando todo lo perteneciente a la sensación, hasta quedarnos sólo con la intuición pura y con la forma de los fenómenos (A.22).

Las formas puras de la intuición sensible son el espacio y el tiempo. La naturaleza del espacio y del tiempo consiste en que son las condiciones de toda representación (síntesis entre la concepción de Leibniz y de Newton, recogiendo las ventajas de ambos y evitando los inconvenientes). Sólo quiero resaltar por lo que se refiere al espacio y al tiempo que Kant descubre la

54. Cfr. : Citado por E. Cassirer, op. cit. , pág. 572. (Refl. 490).

55. Kant, Sueños de un visionario. Cfr.: E. Cassirer, op. cit. , pág. 573.

56. Utlizo la edición de Alfaguara, Madrid, 1985.

57. Kant, A. 19- B.33. 
necesidad de considerar el espacio como dado a priori y de esta forma halla el hilo conductor que le permite deducir el resto de los elementos a priori de nuestro conocimiento y la naturaleza del yo transcendental ${ }^{58}$.

Toda impresión que llega a nosotros es organizada espacio-temporalmente. El entendimiento es la capacidad de pensar el objeto dado en la intuición. Sensibilidad y entendimiento son ambos necesarios. "Los pensamientos sin contenido son vacíos; las intuiciones sin conceptos son ciegas" (A.51).

Conviene tener en cuenta que Kant pretendía resolver el problema de la inducción planteado por Hume para restablecer el valor de los conceptos de causa, sustancia... etc., es decir, de las categorías. Preocupación de Kant es conocer el origen, la extensión, la legitimidad y el valor de los conocimientos a priori y, por tanto, de las formas y de los principios a priori. (A.4):

"Perseguiremos, pues, los conceptos puros hasta sus primeros gérmenes y rudimentos en el entendimiento humano, donde existían precedentemente, esperando que la experiencia fuera la ocasión de su desenvolvimiento, y que, libres por ese mismo entendimiento de las condiciones empíricas que le son inherentes, lleguen a ser expuestos en toda su pureza"59.

Los conceptos puros quedan excluidos de la crítica humeana, piensa Kant, ya que, no sólo los usamos de hecho en los juicios empíricos objetivos, sino que, en virtud de la "deducción transcendental" se garantiza el derecho a usarlos ${ }^{60}$. Sólo mediante las categorías se da cuenta de la posibilidad de la experiencia objetiva.

¿Cuál es el origen de las categorías?. Las categorías no proceden de las representaciones de la sensibilidad (Locke), ni de cualidades síquicas (Hume); ni son innatas ${ }^{61}$, ni proceden de ninguna intuición intelectual que pudiese captar lo inteligible ${ }^{62}$. Se originan a partir de los juicios pero no en cuanto a los contenidos, sino por la forma judicativa: "Cada categoría determina los objetos a los que se refiere de un modo análogo a como la forma del juicio correspondiente enlaza sus contenidos"63: "Lo primero que se nos tiene que dar para conocer todos los objetos a priori es lo diverso de la intuición pura; lo segundo es la síntesis de tal diversidad mediante la imaginación, pero ello no nos proporciona todavía conocimiento. Los conceptos que dan

58. Cfr.: M. Fartos Martínez, “La teoría kantiana de la ciencia” art. cit. , pág. 75.

59. Kant, Introducción a la Analítica.

60. M. Fartos Martínez, art. cit. , pág. 77-78.

61. Más adelante discutiremos este concepto.

62. Kant, C. R. P. , A-IX, pág. 8; A-1, B-1, pág. 41-42; B-127-128, pág. 127-128; B-167, pág. 176; A-271, B-327, pág. 283.

63. E. Chávarri, "Incursiones de la Lógica en la Crítica", en Estudios filosóficos, 83,vol. XXX, enero-abril,Valladolid, 1981, pág. 52. 
unidad a esa síntesis pura y que consisten sólo en la representación de esta necesaria unidad sintética son el tercer requisito para conocer un objeto que se presente, y se basan en el entendimiento. La misma función que da unidad a las distintas representaciones en un juicio proporciona también a la mera síntesis de diferentes representaciones en una intuición una unidad que en términos generales, se llama concepto puro del entendimiento. Por consiguiente, el mismo entendimiento y por medio de los mismos actos con que produjo en los conceptos la forma lógica de un juicio a través de la unidad analítica, introduce también en sus representaciones un contenido transcendental a través de la unidad sintética de lo diverso de la intuición; por ello se llaman estas representaciones conceptos puros del entendimiento, y se aplica a priori a objetos, cosa que no puede hacer la lógica general" (A.79, B.105).

La función del pensamiento en relación a los juicios la establece Kant en función de la cantidad, de la cualidad, de la relación y de la modalidad ${ }^{64}$.

"Reducir la síntesis a conceptos es una función que corresponde al entendimiento"... (A.78). "La síntesis pura, en su representación general, nos proporciona el concepto puro del entendimiento" (B.104).

A partir de aquí, se establece que la misma función que unifica las representaciones en un juicio, "proporciona también a la mera síntesis de diferentes representaciones en una unidad que, en términos generales, se llama concepto puro del entendimiento"(A.79).

Según esto, Kant establece la tabla de las categorías (B.106) en relación a la tabla de los juicios posibles.

Dejamos a un lado el problema de completud, en el sentido de si son doce o más o menos categorías y el tema del yo como apercepción transcendental. Tampoco queremos detenernos en examinar si el origen de las categorías es o no pertinente a la epistemología ${ }^{65}$.

Por otra parte, es necesario tener en cuenta también los límites de la razón. Los únicos objetos del conocimiento son los fenómenos, es decir, los objetos del mundo físico, empíricamente observables. No podemos llegar al conocimiento de un mundo último constituido por noúmenos. Si se intenta transcender el mundo de los fenómenos caemos en antinomías y paralogismos. Toda descripción del mundo debe limitarse a los fenómenos, a la experiencia.

64. Kant, C. R. P. , B.106, pág. 113.

65. Cfr.: E. Chávarri, art. cit., pág. 54-55. Cfr.: las dificultades que este autor plantea a Kant en las páginas citadas. 
Resumiendo, en cuanto es posible, la posición de Kant sobre el problema que venimos analizando, la relación entre el pensamiento y la realidad, tendríamos, que frente a Hume ${ }^{65 a}$ :

a) "No todo conocimiento científico se genera en la experiencia. Algunos contenidos mentales simples, en concreto, las intuiciones puras de espacio y tiempo; y las categorías: sustancia, causa, acción recíproca, etc. , son a priori".

b) "No todo conocimiento científico se funda en la experiencia. Algunas proposiciones esenciales de la trama de nuestro conocimiento científico son a priori. A destacar, las analogías de la experiencia (los fenómenos están sometidos a reglas a priori que determinan su relación mutua en el tiempo), particularizadas, según que el modo del tiempo sea la permanencia, la sucesión o la simultaneidad en los principios de sustancialidad(los diferentes principios de conservación serían ejemplificaciones suyas), causalidad y de acción recíproca. Nótese la correspondencia con los tres principios de los Principios de Newton"

c) "Todo conocimiento ha de ser confirmado por la experiencia. Si tal cosa no ocurre las categorías y principios respectivos funcionarían en el vacío, que es lo que ocurre en la metafísica".

\section{7.- El a priori en Husserl}

A lo largo de toda la extensa obra de Husserl descubrimos un único objetivo: hallar el fundamento inconmovible y sólido de nuestro conocimiento frente a los escépticos y frente al sicologismo y al historicismo ${ }^{66}$. Su filosofía adopta el término de fenomenología. "Fenómeno" es el ser en cuanto que se revela o manifiesta a la conciencia. Justo en este manifestarse consiste el ser que busca la conciencia, el ser en su "esencialidad" racional. Lo que pretende la fenomenología es describir estas esencias inmanentes al pensamiento, tan claras y evidentes que impiden toda duda o cualquier tipo de escepticismo.

La fenomenología presenta un doble aspecto: es un método y es una teoría. Como método se refiere a aquellos procedimientos que hacen de la filosofía una "ciencia rigurosa" que sirva de base a las ciencias particulares;

65a. Cfr. M. Fartos Martinez, op. cit.,pág. 78.

66. Para esta exposición, además de las obras de Husserl, utilizo, E. P. Lamanna, La filosofia del novecento, Felice de Monnier, Firenze, 1967; L. Kolakowski, Husserl y la búsqueda de la certeza, A. E. , Madrid, 1977; C. Díaz, Husserl (Intencionalidad y fenomenología) m Zero, vizcaya, 1971; F. Montero Moliner, Retorno a la fenomenología, Anthrophos, Barcelona, 1987; J. San Martín, La fenomenología de Husserl como utopía de la razón, Anthrophos, Barcelona, 1987. 
como teoría pretende descubrir la estructura del pensamiento("lógica pura") y cómo construye la verdad absoluta (gnoseología), a la vez que se convierte también en ontología al especificar el sentido racional del universo ${ }^{67}$.

La fenomenología no renuncia a la experiencia, sino que la conciencia se abre al mundo vivido con el fin de descubrir "en aquella movilidad y variedad de las experiencias vividas algo sólido e intemporal, algo universalmente válido, absolutamente verdadero, esencialmente real"68.

Ya en su filosofía de la Aritmética ${ }^{69}$, dependiendo de F. Brentano, señala dirección de sus investigaciones tratando de descubrir los principios últimos que justifiquen la validez del conocimiento y, en especial, el origen y los principios fundamentales de las verdades matemáticas. Pero aquí todavía mantiene el punto de vista sicologista de Brentano; este aspecto sicológicosubjetivo lo irá abandonando debido a las críticas de Frege y de Natorp, y al conocimiento de Bolzano, para desarrollar el aspecto lógico-objetivo. Si la filosofía quiere cumplir su cometido deberá fundarse en el concepto de ser en sí, válido, independientemente de que lo conozca una conciencia. Todavía se mantiene el concepto de intencionalidad como la característica esencial de la conciencia.

El rechazo del sicologismo se verifica en las Investigaciones lógicas de la manera más contundente (Prolegómenos). Se trata de hallar "una teoría de los sistemas deductivos formales"... "Tanto más me inquietaba, pues, la fundamental duda de cómo se compadecía la objetividad de la matemática -y de toda ciencia en general- con una fundamentación sicológica de lo lógico. $\mathrm{De}$ este modo empezó a vacilar todo mi método, que se sustentaba en las convicciones de la lógica imperante... y me vi impulsado en medida creciente a hacer reflexiones críticas generales sobre la esencia de la lógica y principalmente sobre la relación entre la subjetividad del conocer y la objetividad del contenido del conocimiento"70.

Se trata de superar el mundo de los hechos externos y de la experiencia externa para descubrir el mundo de las ideas y de los valores como objetos irreductibles a cualquier experiencia ${ }^{71}$, afirmando que estas ideas son las "unidades ideales de significación" y la filosofía será la lógica pura.

La lógica pura es la forma del conocimiento a priori.

Husserl expone su programa en el capítulo "Prolegómenos a una lógica pura". Se trata de buscar "las condiciones de la posibilidad de la verdad en

67. Cfr.: P. Lamanna, op. cit. , pág. 267.

68. P. Lamanna, op. cit. , pág. 267.

69. E. Husserl, Philosophie der Arthmetik (Husserliana, 12).

70. E. Husserl, Inv. Lóg. , T.I., A. U. , Madrid, 1985, pág. 21-22.

71. Cfr. : Prólogo de J. Gaos a las Medit. Cart. , F. C. E. , Madrid-México, 1985, pág. 12-13. 
general y de la unidad deductiva en general... condiciones a priori del conocimiento, que pueden ser consideradas e investigadas abstrayendo de toda relación con el sujeto pensante y con la idea de la subjetividad en general"72.

Para conseguir la objetividad del conocimiento es preciso determinar "los conceptos primitivos" y establecer su origen fenomenológico, es decir, descubrir sus esencias (Inv. Lóg. \& 67). "Las teorías y leyes categoriales constituyen más bien, en su integridad ideal, el fondo universal, de donde cada determinada teoría válida extrae los fundamentos ideales de su esencialidad correspondientes a su forma; estos fundamentos son las leyes a las cuales se ajusta en su curso y partiendo de las cuales puede ser justificada en última instancia como una teoría "válida" por lo que toca a su forma"73. Lo que pretende el filósofo es "poner en claro la esencia de "cosa", "proceso", "causa", "efecto", "espacio", "tiempo", etc. , y la admirable afinidad que esta esencia tiene con la esencia del pensamiento, que puede ser pensada; con la del conocimiento, que puede ser conocida; con la de las significaciones, que puede ser significada"... ${ }^{74}$.

Ahora bien, para poder fundamentar la lógica pura, estas formas lógicas objetivas deben referirse y unificarse en la conciencia(subjetivación del platonismo). La conciencia se presenta como apertura al ser objetivo y como actividad a través de la cual el ser se manifiesta. Se daría, por tanto, una "correlación" universal a priori entre la objetividad del ser y la subjetividad de la conciencia ${ }^{75}$. La conciencia se entiende aquí no en el sentido empírico sino como conciencia pura. No es tampoco la conciencia transcendental kantiana, sino intencional. ¿Cómo pueden darse las estructuras lógico-objetivas a la conciencia? : "Al sentido de todo lo contingente es inherente tener precisamente una esencia y por tanto un eidos que hay que aprehender en su pureza, y este eidos se halla sujeto a verdades esénciales de diverso grado de universalidad"76.

Sin embargo, "el poner y ante todo el aprehender intuitivamente esencias no implica en lo más mínimo el poner existencia individual alguna; las puras verdades esenciales no contienen la menor afirmación sobre hechos, por lo que tampoco cabe concluir de ellas solas la más insignificante verdad de hecho"77.

72. E. Husserl, Inv. Lóg. , \& 65, pág. 197-198. Cfr. : P. Lamanna, op. cit. , pág. 280.

73. E. Husserl, Inv. Lóg. , \& 68, pág. 203.

74. E. Husserl, Inv. Lóg. , \& 71, Pág. 209.

75. Cfr. : P. Lamanna, op. cit. , pág. 283. Este es el tema de la segunda parte de las Inv. Lóg.

76. E. Husserl, Ideas, F. C. E. , Madrid, 1985, pág. 19.

77. E. Husserl, Ideas, pág. 23-24. 
La actitud fenomenológica consiste en mirar directamente la conciencia, sin tener en cuenta el mundo, para descubrir la auténtica realidad de la conciencia.

La conciencia es así el lugar o el medio para alcanzar la objetividad ideal (esencia). "Al cogito mismo es inherente, como inmanente a él, un "mirar a" el objeto, que, por otra parte, brota del "yo", el cual no puede, pues, faltar nunca. Este "mirar a" algo el yo es, según el acto, en la percepción percipiente, en la ficción, fingidor, en el querer, volente, en el agrado, un mirar con agrado, etc." 78 .

Hablar de la conciencia intencional significa hablar de una conciencia que mediante sus operaciones "establece la relación constitutiva de la "presencia" del objeto, o incluso del mismo objeto"79.

Entre conciencia y objeto se establece una correlación esencial. La conciencia es movimiento hacia el objeto; el objeto es "presencia" a la conciencia. No quiere decir esto que el objeto intencional sea un constitutivo real de la conciencia, sino, otra cosa diferente de la conciencia y presente a ella en la experiencia vivida. El análisis fenomenológico consiste en buscar qué cosa del objeto mismo como tal esté contenido en la experiencia vivida en su aparecer. El aparecer de la cosa no es la cosa que aparece. Nosotros vivimos el aparecer como un hecho complejo de la conciencia, mientras que las cosas se nos aparecen como pertenecientes al mundo" 80

Se trata, por tanto, de precisar qué sea el objeto intencional.

En la Investigaciones lógicas ${ }^{81}$ expone ya la teoría del "significado" como anticipación de la teoría de la esencia y de su intuición desarrollada en las Ideas. Cuando Husserl habla de "significado" se refiere a aquello que la conciencia intuye en una expresión. Es el objeto ideal, idéntico y permanente que se ofrece a la conciencia. "Esta verdadera identidad que aquí afirmamos, no es otra cosa que la identidad de la especie ... Las significaciones constituyen... una clase de conceptos en el sentido de objetos universales" 82. Esta universalidad no debe ser confundida con la generalidad empírica. En Ideas, el "significado" es entendido como esencia y la conciencia, en cuanto intencionalidad, es intuición de esencias ${ }^{83}$.

En relación a esto, y como elemento fundamental de la fenomenología está el concepto de la epojé o reducción eidética ${ }^{84}$.

78. E. Husserl, Ideas, pág. 83.

79. P. Lamanna, op. cit., pág. 288.

80. Cfr. : E. Husserl, Inv. Lóg. , Ensayo V, Vol. II, pág. 478.

81. E. Husserl, Inv. Lóg. , Vol. II, pág. 606 y ss.

82. E. Husserl, Inv. Lóg., Vol. I, pág. 288.

83. Cfr. : El capítulo ${ }^{\circ}$ de la sección $\mathrm{I}^{\mathrm{a}}$ de Ideas, pág. 17 y ss.

84. Cfr. : E. Husserl, \& 32, pág. 73. 
Este concepto significa poner "fuera de acción" o entre paréntesis el mundo en cuanto existencia espacio-temporal, si bien, esta reducción deberá realizarse a través de un proceso gradual. Convendría quizás hablar más bien de reducciones fenomenológicas. Así, a través de estas reducciones, llegamos a un residuo fenomenológico, que es la conciencia, la conciencia pura. Una vez liberada del mundo (puesto entre paréntesis) la conciencia se preguntará por el sentido del mundo como correlato de la conciencia, como objeto intencional. Cuando la conciencia se convierte en conciencia transcendental, asume el papel de "constituir" el mundo ${ }^{85}$. Llegados a este punto, se plantea la pregunta fundamental, a nuestro juicio: ¿Se reduce la estructura real a la estructura transcendental de la conciencia?

La clave para responder a esta pregunta la encontramos en la correlación entre el acto del pensamiento que se dirige a un contenido y el contenido mismo como pensado, es decir, en cuanto término intencional del pensamiento. En el fondo se trata de saber "cómo a través de leyes esenciales absolutamente estables el objeto existente sea el correlato de las conexiones de la conciencia, del contenido esencial bien determinado, y como, a su vez, el ser de tales conexiones sea el equivalente del objeto existente"

¿Es la realidad objetiva la que se constituye en la experiencia del sujeto transcendental? ${ }^{87}$.

La tesis de Husserl es que el ser objetivo se constituye exclusivamente en el ámbito y por obra de la conciencia. Se trata del idealismo transcendental. Con ello se establece la prioridad de la conciencia. Hablar de idealismo es hablar de la creatividad de la conciencia. Así como anteriormente se había planteado el problema sobre la intencionalidad de la conciencia como presencia del objeto al sujeto, como intuición de esencias, aquí (en la lógica), se insiste en el concepto de creatividad:

"El mundo, y, en particular, todo ser de cualquier especie que sea, no viene de fuera a la vida de mi conciencia; todo "de fuera" es aquello que está

85. Cfr.: E. Husserl, Ideas, pág. 115-116; 117-118. Las fases que se dan hasta la constitución del mundo son:

a)Aceptación dogmática de la existencia.

b) Reducción del mundo al ser ideal.

c) Afirmación de la conciencia pura como residuo fenomenológico.

d) Recuperación del mundo reducido en la conciencia pura mediante la actividad transcendental constitutiva; Cfr. : P. Lamanna, op. cit. , pág. 305. Puede verse también L. Kolakowski,

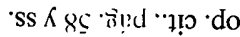

86. P. Lamanna, op. cit. , pág. 307.

87. Cfr. : E. Husserl, Ideas, pág. 306 y ss. Kant habla de lả constitución dél mundo universal y necesario: la materia procede del mundo; las formas son estructuras del sujeto. En Husserl la materia es la abstracción del flujo vital y la forma, el contenido noemático de la intencionalidad. (Cfr.: P. Lamanna, op. cit. , pág. 307). 
"dentro" y tiene su verdadero ser por ser dado y verificado dentro" . "Todo ente se constituye en la subjetividad de la conciencia... Para mi no hay ningún ser ni ningún ser de tal o cual manera, efectivamente existente o posible, si no es válido para mi"s8.

Como dice Kolakowski "el concepto de constitución sigue siendo vago: no es una creación ex nihilo, es más bien el acto de dotar al mundo de sentido. En la conciencia transcendentalmente reducida, sin embargo, cada acto de alcanzar el objeto es un acto de suplantarlo con significado; cualquier sentido es el producto de la constitución, incluyendo, en especial, el sentido de un sujeto como existente" 89 .

En las Meditaciones cartesianas, ${ }^{90}$ Husserl pretende asumir en la conciencia transcendental el mundo existente puesto por mi entre paréntesis y recuperarlo en un proceso en el que el ser se constituye de forma indefinida. Puesto que este aspecto no es el objeto de este análisis, lo dejo para otra ocasión. Lo que me importa destacar es que " los objetos son sedimentaciones... de actos creativos de la conciencia, siendo esta última la fuente última de su forma cristalizada"91.

Al principio de este apartado habíamos declarado que el objetivo de Husserl era la búsqueda de la certeza, de un conocimiento absolutamente seguro. Después de seguir sus pasos llegamos a la conclusión de que la "objetividad" sólo se obtiene en la conciencia transcendental. Como decíamos, el problema de Husserl es hallar la fuente de la certeza absoluta. ¿Dónde se encuentra?. En la conciencia transcendental. Si hay una inmediatez absoluta, no es necesario "el puente" entre la representación y el objeto. No hay mediación noesis y noema. El contenido es inmanente y transparente al sujeto.

En lo dicho está presente la evolución del pensamiento de Husserl.

\section{III.- CONSIDERACIONES ACTUALES}

\section{1.- N. Chomsky y P. D. Eimas}

La disputa clásica entre racionalismo y empirismo encuentra en la actualidad un representante que desde la lingüística se decanta a favor del innatismo: N. Chomsky. Exponemos las líneas generales de su innatismo y lo que

88. E. Husserl, Lógica, Centro de Est. Fil. , México, 1962, \& 94, pág.243 y 245.

89. L. Kolakowski, op. cit. , pág. 58.

90. E. Husserl, Medit. cart. , F. C. E. , Madrid,1958.

91. L. Kolakowski, op. cit. , pág. 59. 
nos parece una corroboración experimental, por lo que se refiere al lenguaje, del mismo, pese a las críticas que se le vienen haciendo a su teoría.

Chomsky se preocupa del problema de la competencia linguiística. Sus críticas se dirigen primero a la concepción empirista respecto a la adquisición del lenguaje por parte del niño. El modelo que se ataca es el de B. F. Skinner. Para éste (y para los empiristas), la adquisición del lenguaje se explicaba según el modelo del estímulo y respuesta: la repetición de una palabra el estímulo sensible adecuado, y, mediante el debido "refuerzo" ejercido por padres y educadores, el niño adquiriría la "estructura de hábitos" mediante la cual asocia la palabra con el estímulo correspondiente.

Chomsky critica este esquema explicativo, en primer lugar, por la esca$s e z$ de datos con los que el niño cuenta en relación al alto nivel de competencia lingüística que posee en tan breve tiempo:

"La competencia lingüística de un adulto, o incluso de un niño pequeño es tan elevada que debemos atribuirle un conocimiento del lenguaje que se extienda mucho más de lo que él haya aprendido. En comparación con el número de frases que un niño puede pronunciar o interpretar con facilidad, el número de segundos que hay a lo largo de una vida es ridículamente pequeño. Por lo tanto, los datos disponibles como estímulo de entrada representan apenas una diminuta muestra del material lingüístico que ha sido dominado a la perfección, como lo indica el rendimiento efectivo ${ }^{92}$.

En segundo lugar la crítica se refiere "al aspecto creador del uso del lenguaje" que se advierte en el usuario humano: "Cuando hablo del aspecto creativo del uso del lenguaje me estoy refiriendo a la capacidad de producir e interpretar nuevas frases con independencia del "estímulo-control", es decir, los estímulos externos o los estados internos identificables por separado. En este sentido el uso normal del lenguaje es "creativo", como fue señalado ampliamente por la tradicional teoría lingüística racional. Las frases utilizadas en el habla cotidiana no son frases "familiares", desde el punto de vista de cualquier proceso generalizador que se conozca ${ }^{93}$.

92. N. Chomsky, Ideas innatas, Cfr. : N. Chomsky, El lenguaje y el entendimiento, Seix Barral, Barcelona, 1983, pág. 55. Como corroboración de la crítica de Chomsky a la visión empirista cito el siguiente ejemplo citado por R. Riedl en su Biología del conocimiento, Labor, Barcelona, 1983, pág. 42, nota 76: "si se supone que, en el caso del perro, sólo hay 16 conexiones entre el oído interno, el cerebro y la musculatura de la glándula salival, entonces resultan 16! (16 factorial) posibilidades de permutación, es decir, unas 2.10 elevado a 13 , unos veinte billones. La vida de un perro (unos 3.10 elevado a 8 segundos) no es lo suficientemente larga como para lograr de ese modo una sola asociación".

93. N. Chomsky, Ideas innatas, pág. 55. 
Cuando Chomsky habla del aspecto creador en el Lenguaje y el entendimiento ${ }^{94}$ se refiere a "la capacidad por la que el hombre se distingue de los demás animales, de expresar pensamientos nuevos y entender expresiones de pensamiento enteramente nuevas, y eso dentro del marco de una "lengua instituida, una lengua que es un producto cultural sujeto a leyes y principios que le son en parte peculiares y en parte son el reflejo de las propiedades generales del entendimiento".

La teoría de Chomsky para explicar el lenguaje humano consta de una serie de hipótesis:

a) Como consta en la cita anterior, se poseen de forma innata principios y leyes generales propias del entendimiento humano.

b) "Estos principios que determinan la forma de la gramática y que seleccionan una gramática de la forma adecuada sobre la base de ciertos datos constituyen un campo que, siguiendo un uso tradicional, podría denominarse "gramática universal" "95.

c) "El estudio de la gramática universal, entendida de esta manera, forma parte del estudio de la naturaleza de las capacidades intelectuales humanas" $"$.

d) Se establece la distinción entre "estructura profunda" y "estructura superficial". La estructura superficial de la oración “es la organización de la misma en categorías y frases que está directamente asociada con la señal física, y la estructura profunda subyacente... es también un sistema de categorías y frases, pero de un carácter más abstracto"97.

e) Existe un conjunto de principios mentales que expresan el sentido de una oración y que dirige la realización efectiva de tal oración a través de la señal física, relacionándose ambas a través de operaciones formales llamadas transformaciones gramaticales ${ }^{98}$.

f) El poseer de forma innata los principios de la gramática universal, es lo que capacita al niño para el aprendizaje de cualquier lengua particular humana.

Las ideas fundamentales de N. Chomsky, abiertas a posibles investigaciones, han generado, de hecho, una serie de corrientes o líneas de profundización tanto teóricas como experimentales. Vamos a referirnos, brevemente,

94. N. Chomsky, El Leng. y el Ent. , pág. 25. El subrayado es mío.

95. N. Chomsky, El Leng. y el Ent., pág. 56.

96. Ibidem.

97. N. Chomsky, El Leng. y el Ent. , pág. 57-58; 178-179; 209.

98. Cfr. : N. Chomsky, op. cit. , pág. 57 y 125. 
a una de estas investigaciones empíricas de confirmación, aunque sin entrar en todos los detalles ${ }^{99}$.

$\mathrm{El}$ autor trata de explicar el rápido aprendizaje y uso que el niño hace del lenguaje atribuyéndolo a que "ciertos conocimientos y capacidades innatas subyacen al uso del lenguaje"100.

Dice P. D. Eimas: "En estudios sobre la percepción del habla en bebés hemos comprobado que los infantes poseen una dotación muy rica de mecanismos perceptivos innatos, adoptados a las características del lenguaje humano que les prepara para el mundo lingüístico al que tendrán que adaptarse" $" 101$.

Diversos experimentos tratan de comprobar "la información acústica que basta para señalar la distinción entre la consonante oclusiva sonora que inicia la palabra bar y la consonante oclusiva sorda que inicia la palabra par"... "El intervalo entre la liberación del aire y el inicio de la vibración de las cuerdas vocales, esto es, la sonorización, se conoce como tiempo de emisión de la voz; contiene la información acústica crucial que permite al oyente distinguir bar de par"... ${ }^{102}$.

Sin embargo, "no existe un valor único de parámetros acústicos que caracterice a cada forma"... "No obstante, a pesar de los sonidos correspondientes a cada fonema, poco nos cuesta decidir si se ha dicho par o bar. De hecho, podemos detectar la variación de la señal y formular juicios categóricos sobre la calidad fonémica". "Resultados experimentales confirman la idea de que en la percepción del habla solemos capturar categorías fonémicas discretas y no la variación continua de cada parámetro acústico: percibimos el habla categóricamente" 103 .

La pregunta que se hace el investigador es la siguiente: “¿Qué proporción de este mecanismo de percepción categórica que nos permite percibir el habla de modo fiable, a pesar de la falta de predicción de la señal hablada, es innata?"104.

Por supuesto, que el contexto lingüítico tiene una poderosa influencia. Pero, es evidente que ciertas distinciones fonémicas están presentes en las lenguas de todo el mundo. El autor de este artículo y sus colegas deducen de este hecho que quizá subyacen "a la percepción categórica del habla fuertes

99. P. D., Eimas, "Percepción del habla en la primera infancia", en Inv. y Cienc. , n 102, marzo, 1985, pág. 24-31. Hago simplemente la exposición de resultados.

100. P. D. Eimas, art. cit. , pág. 24.

101. Ibidem.

102. Ibidem.

103. P. D. Eimas, art. cit. , pág. 24-26.

104. P. D. Eimas, art. cit. , pág. 26. 
determinantes biológicos modificados por la experiencia lingüística posterior"105.

Para confirmar esta hipótesis emprenden diversos experimentos con bebés que aún no hablaban (para evitar las influencias de la lengua de sus padres).

Se trataba de medir la percepción del tiempo de emisión de voz, o la respuesta a cambios de la frecuencia de emisión del segundo y tercer formantes, que indican diferencias en el punto de articulación de una consonante. Las respuestas a estos experimentos son positivas. Parece difícil justificar este hecho atribuyéndolo al aprendizaje. De ahí que los investigadores expliquen "que la categorización se produce porque el niño nace con mecanismos perceptivos que sintonizan con las propiedades del habla. Estos mecanismos no serían sino los precursores de las categorías fonémicas que más tarde permitirán al niño convertir la señal variable del habla en una serie de fonemas, y más tarde, en palabras y significados" 106 .

En el caso de que estos mecanismos perceptivos fueran de carácter biológico, deberían ser universales y, por tanto, aparecer en los bebés de diferentes culturas lingüísticas. Estudios con bebés guatemaltecos(1975), keniatas (1976) y angloparlantes vienen a confirmar que "los bebés de todo el mundo están dotados de una sensibilidad innata a esas tres categorías de sonorización, sean o no importantes dichas distinciones en sus respectivas lenguas maternas"107.

Baste esto como corroboración de la tesis fundamental de Chomsky. Podrían citarse otros experimentos. La conclusión sería que "un bebé nace dotado de muchos de los cimientos de su posterior percepción y comprensión del habla. Puede que... esas capacidades perceptivas innatas hayan evolucionado específicamente hacia la percepción y comprensión del habla. Constituyen una respuesta evolutiva a la necesidad de que cada niño adquiera la lengua y cultura de sus padres en una etapa lo más temprana posible de su vida"108.

\section{2.- Epistemología evolucionista de Vollmer}

Sobre este tema es necesario tener en cuenta la posición que G. Vollmer mantiene en : "Mesocosmos y conocimiento objetivo: Sobre los problemas que resuelve la gnoseología evolutiva" 109 .

105. Ibidem.

106. P.D. Eimas, art. cit. , pág. 27.

107. P. D. Eimas, art. cit. , pág. 29.

108. P. D. Eimas, art. cit. , pág. 31.

109. G.Vollmer, en K. Lorenz-F. M. Wuketits, La evolución del pensamiento, Argos-Vergara, Barcelona, 1984. 
El objetivo que Vollmer se plantea es cuádruple: exponer las tesis fundamentales de la epistemología evolutiva, qué es lo que afirma esta posición, los problemas filosóficos que resuelve o aclara y, por último, hacer ver que esta teoría no sólo es útil sino que está vinculada a diferentes ciencias.

Vollmer comienza aceptando que el conocimiento existe como un hecho empírico entendiendo como conocimiento la siguiente definición operativa: "el conocimiento expresa una reconstrucción y una identificación adecuadas de las estructuras exteriores en el sujeto"110. A partir de aquí se origina una cascada de preguntas. Pero si aceptamos como hecho la existencia del conocimiento, la pregunta sería: ¿Cómo es posible el conocimiento?.

Una primera respuesta, aceptable por gran parte de filósofos, sería: "El conocimiento humano aparece gracias a una concomitancia de estructuras objetivas (del mundo real) y estructuras subjetivas (del órgano cognoscitivo)"111. La aportación del sujeto puede ser perspectiva, selectiva o constructiva. Se subraya el papel del objeto y del sujeto y, por tanto, se hace hincapié en el ajuste (¡antes adecuación!) entre las estructura subjetivas y objetivas. ¿Cómo entender este ajuste?. He aquí la respuesta de Vollmer:

a) El ajuste es instrumental, es decir, el ojo se ajusta a la luz, a la manera que un instrumento se ajusta a su tarea, en el sentido que el ojo absorbe y elabora las señales que el sol emite. No se puede hablar de que las estructuras cognoscitivas "reproduzcan" o "reflejen" las propiedades del mundo exterior en el sentido fuerte ${ }^{112}$, sino sólo que ofrecen indicaciones sobre el medio para el que son idóneas.

b) Si se da el conocimiento debe darse el ajuste entre las estructuras objetivas y subjetivas. Por otra parte, el conocimiento resulta provechoso, por lo menos en el sentido biológico:aumenta las posibilidades de reproducirse y su aptitud ${ }^{113}$.

c) Se presume un ajuste adecuado entre las estructuras subjetivas y objetivas, un isomorfismo parcial. Así pues, teniendo esto en cuenta, la teoría evolutiva del conocimiento pretende dar respuesta a las siguientes cuestiones:

a) Vollmer acepta como hecho empírico la concordancia parcial entre estructuras subjetivas (nuestro conocimiento) y las estructuras objetivas (el mundo):

110. G.Vollmer, art.cit. , pág.28. Subrayo el hecho de que aceptar en principio una definición presupone en gran medida aceptar lo que se quiere.demostrar.

111. G.Vollmer, art. cit. , pág.29.

112. G. Vollmer precisa, en parte, el concepto de reproducción al que hace referencia K.Lorenz (1941,1943,1973).

113. G. Vollmer, art. cit. , pág. 33. 
"Nuestro aparato cognoscitivo es el resultado de la evolución (biológica). Las estructuras cognoscitivas se ajustan a las estructuras (objetivas) del mundo, porque se han ido formando en la adaptación a ese mundo. Y concuerdan (en parte) con las estructuras reales, porque sólo esa concordancia hizo posible la supervivencia ${ }^{(114}$.

b) Aceptado el planteamiento anterior, se trata de explicar esta concordancia (toda la historia de la filosofía es un intento de explicar esta adecuación).

c) La gnoseología evolutiva da respuesta a esta cuestión a través de la teoría de la evolución. Un problema filosófico se pretende resolver con una teoría científica (!) ${ }^{115}$, hecho que Vollmer considera legítimo.

d) Ahora bien, ¿No caeremos en un círculo vicioso?. ¿Qué es primero, la gnoseología evolutiva o el saber científico?. La respuesta de Vollmer es concisa: puede haber círculo, pero, no es vicioso, ya que, ciencia y teoría del conocimiento se hallan en un intercambio dialéctico. Se trata de ver ambas como "un circuito regulador"116.

e) El ajuste entre las estructuras cognoscitivas y objetivas es el resultado de un proceso de adaptación, gobernado por la mutación y la selección. Se trata de investigar los orígenes filogenéticos y de aquellos órganos genéticamente determinados.

f) La adaptación del organismo al medio no es nunca ideal, primero, porque no es necesaria para la supervivencia; segundo, porque, ello sólo sería posible, a cambio de grandes esfuerzos; tercero, porque la presión mutacional no sólo permite el proceso de adaptación, sino que también se opone a él; y, cuarto, porque el mantenimiento de una supuesta adaptación ideal significa un grado de rigidez tan extremo que no se tendrían oportunidades ante los cambios del medio ambiente. Pero en un universo evolutivo como el nuestro los cambios en el medio ambiente son inevitables; harían que cualquier adaptación fuese, a largo plazo, todo menos "ideal"117.

g) La teoría evolutiva del conocimiento pretende explicar la imperfección del conocimiento.

h) Pero la imperfección del conocimiento debe de hallarse dentro de unos límites; no puede ser excesivamente mala. El ajuste "ha de ser adecuado a la supervivencia"118. Esto permite entender el aparato cognoscitivo

114. G. Vollmer, art. cit. , pág. 35; El texto es de 1975, pág. 102.

115. La admiración es nuestra frente al planteamiento de Vollmer. ¿Es la teoría de la evolución una teoría científica?. ¿Hasta dónde?

116. G.Vollmer, art. cit., pág. 37.

117. G.Vollmer, art. cit., pág. 38.

118. G.Vollmer, art. cit., pág. 39. 
como un conjunto de hipótesis sobre el mundo, lo que nos permite decir que la evolución es en el plano gnoseológico "un proceso de conjeturas y refutaciones"119.

i) Es este proceso de conjeturas y refutaciones lo que nos lleva al isomorfismo parcial. No tenemos seguridad sobre la verdad $\mathbf{u}$ objetividad de nuestro conocimiento; sólo tenemos indicios y criterios que nos orientan.

j) La teoría evolutiva del conocimiento se relaciona con el problema de las ideas innatas. Pero al hablar de lo innato, la teoría evolutiva del conocimiento se ocupa sólo de conceptos e hipótesis como estructuras cognoscitivas, pero no de valoraciones o de normas ${ }^{120}$. Y, aquí, justamente nos encontramos con Kant.

k) Para Kant el a priori es independiente de toda experiencia y, además, necesariamente verdadero. Para la gnoseología evolutiva, es independiente de toda experiencia individual, es dado genéticamente, pero es el producto de todo el proceso evolutivo; es un aposteriori filogenético. Además, no es infalible, sino, generalmente, correcto.

1) Se admite el saber apriorístico, pero, en contra de Kant, este saber "no es necesariamente verdadero" 121 . No es necesariamente verdadero, pero aspira a un conocimiento de la realidad tal como es, superando lo meramente fenoménico.

m) Frente a Kant (el hombre legislador de la naturaleza) reduce al hombre a un simple observador de la realidad.

Vollmer, después de exponer las tesis fundamentales de la epistemología evolucionista especifica también lo que no dice esta teoría.

Algunas de las cosas que no afirma son las siguientes:

a) "La gnoseología evolutiva no pretende resolver, y ni siquiera abordar, todos los problemas epistemológicos"122.

b) El que no sea completa no quiere decir que renuncie al nivel ontológico. Es una variante del realismo ontológico, que denominan "realismo hipotético" (Campbell, Lorenz y Vollmer) y que, aunque se relaciona con el realismo crítico, no se identifica con él. Aquí se identifica el carácter hipotético de todo conocimiento: incluso la existencia del mundo es una conjetura (aunque bien fundamentada).

c) La diferencia entre sujeto y objeto no significa que el mundo esté multiplicado ontológicamente (Vollmer defiende la teoría de la identidad).

119. Ibidem. Cfr. : K. Popper, Conj. y Ref. y C. Obj.

120. Cfr. : G. Vollmer, art. cit. , pág. 40.

121. Ibidem.

122. G. Vollmer, art. cit , pág. 42. Cfr. : las páginas siguientes. 
d) No se afirma que "todo saber humano esté determinado genéticamente (o sea: biológicamente) ${ }^{123}$; lo que se afirma es que lo biológico condiciona y determina, parcialmente, el conocimiento. La estructura cognoscitiva surge como un instrumento de supervivencia en un ambiente determinado ("mesocosmos"). No obstante, se puede traspasar el mesocosmos estableciendo hipótesis y teorías.

e) Hay una clara diferencia entre el conocimiento que surge de la experiencia (biológicamente determinado) y el conocimiento científico (no determinado genéticamente).

f) "La gnoseología evolutiva no explica o describe la evolución del conocimiento humano, sino, únicamente la evolución de las facultades cognoscitivas"124.

g) Esto no significa que se niegue la evolución cultural. Aún reconociendo diferentes leyes de la evolución cultural y biológica, existen grandes relaciones entre ellas.

h) Las teoría evolutiva del conocimiento defiende elementos pragmáticos del conocimiento, pero esto no supone una concepción pragmática de la verdad.

i)"El conocimiento humano, pese a ser único como hecho, no puede también ser único por principio" 125 . (En la naturaleza existen diferentes sistemas de procesamiento de la información).

j) No se afirma que el conocimiento, el pensamiento, el lenguaje, sean necesarios tal como son, sino que "bajo las condiciones iniciales dadas... el conocimiento humano surgió conforme a leyes naturales"126.

k) La gnoseología evolutiva carece de consecuencias éticas directas.

Una vez consideradas las tesis fundamentales de la gnoseología evolutiva y de aquello que no dice, me parece oportuno seguir a Vollmer sobre el tema del mesocosmos y la evidencia.

Vollmer considera que nuestro aparato cognoscitivo se ha ido adaptando a lo largo del proceso evolutivo no al mundo sino a "un recorte del mundo real", a su "nicho cognoscitivo". Así pues, dice, "llamaremos mesocosmos" al nicho cognoscitivo del hombre. Nuestro mesocosmos es así esa parte del mundo real a la que nos sobreponemos con nuestras percepciones y nuestras acciones, sensorial y motóricamente" 127 .

123. G. Vollmer, art. cit. , pág. 43.

124. G. Vollmer, art. cit. , pág. 44.

125. G. Vollmer, art. cit. , pág. 46.

126. Ibidem.

127. G. Vollmer, art. cit. , pág. 47-48. 
El mesocosmos sería el "mundo de las dimensiones medias", pero, teniendo en cuenta que no es cuestión de metros, que se trata de un concepto antropocéntrico, que sus límites no están claramente definidos y que a él se adaptan nuestras estructuras cognoscitivas ${ }^{128}$. Este mundo mesocósmico es evidente para nosotros. Pero aquí evidente no significa que una estructura puede ser transformada en una estructura mesocósmica"129.

Llegamos así al realismo constructivo. Hemos de relacionar todo objeto y estructura de la ciencia empírica con las experiencias mesocósmicas. Tal descripción puede expresarse a través de la proyección a la que sigue la reconstrucción. Vollmer parte de la existencia de un isomorfismo parcial en la proyección entre el objeto y la imagen. A partir de una o varias proyecciones debemos reconstruir el objeto. Hemos de reconstruir los objetos exteriores (tridimensionales) a partir de las proyecciones bidimensionales.

Reconstruir significa recuperar toda la información perdida durante la proyección. La percepción es el intento de reconstruir el objeto exterior a partir del caos de las impresiones sensoriales.

$\mathrm{Y}$, nuestro conocimiento, en general, es el intento de "reconstruir en nuestro cerebro esas estructuras reales, es decir, (de) crear modelos internos isomorfos de las mismas"130.

"El proceso cognoscitivo consiste, por lo tanto, en una reconstrucción estratificada de una realidad hipotéticamente postulada, en una liberación progresiva de las limitaciones de nuestros órganos sensoriales"131. Nuestro conocimiento de la realidad se hace necesariamente hipotético. Este modelo se denomina gnoseología proyectiva.

Llegados aquí se nos plantea el problema de la objetividad. Objetivo significa "verdadero y exclusivamente relacionado con el mundo real". Pero, ¿tiene sentido hablar de objetividad, de conocer la cosa en sí en el momento actual? ¿No se reducirá el mundo a nuestra subjetividad?. ¿Tenemos algún criterio que nos permita abrigar esperanzas de conseguir un conocimiento objetivo?

Se ha ha hablado de la intersubjetividad; pero, aún siendo necesaria es insuficiente. Podemos, sin embargo, enumerar otros criterios:

-“Comprensibilidad intersubjetiva: la ciencia no es ningún asunto privado. Los enunciados científicos han de poder ser transmitidos, por lo que han de estar formulados en un lenguaje común.

128. G. Vollmer, art. cit., pág. 48-49.

129. Cfr. : G. Vollmer, art. cit. , pág. 50.

130. G. Vollmer, art. cit., pág. 57. Escribo de en lugar de por.

131. G. Vollmer, art. cit., pág. 60. 
1) Independencia ante el sistema del observador: no sólo el observador, en cuanto a persona, ha de carecer de importancia, sino también su posición, su estado de conciencia, su "perspectiva".

2) Comprobabilidad intersubjetiva: cada cual ha de estar en condiciones de comprobar el enunciado, es decir de convencerse de su verdad, sin tener que aceptarlo por simple acatamiento a una autoridad.

3) Independencia ante el método: la verdad de un enunciado no ha de depender del método utilizado para su comprobación.

4) Independencia ante las convenciones: la verdad de un enunciado no ha de depender de un acto arbitrario (resolución o convención)"132.

¿Qué hay de común entre estos criterios? Es "la independencia de la estructura en cuestión con respecto a determinados cambios, su invariación bajo determinadas transformaciones" 133 . Por tanto, podemos decir que "un enunciado es objetivo sólo cuando él, es decir: su verdad, es invariante con relación a un cambio en las condiciones bajo las cuales fue formulado, cuando es independiente, por tanto, del observador, del sistema de referencia, del método aplicado para comprobarlo y de las convenciones"134. La invariación es un criterio necesario, pero tampoco es suficiente. La objetividad no se puede comprobar definitivamente. Se convierte en una idea regulativa. El criterio de invariación justifica sólo "la conjetura hipotética de que un enunciado es objetivo"135.

Vollmer recurre a justificar esta posición a través de las matemáticas, la sicología de la percepción, la neurofisiología y la física.

En relación al postulado de la realidad se halla el problema de la causalidad. Consideramos importante exponer la tesis de Vollmer al respecto. Conocemos la problemática en torno a esta cuestión: la distinción escolástica entre el post hoc y propter hoc, la crítica de Hume, la posición de Kant...

El problema fundamental sería el siguiente: si interpretamos los acontecimientos en clave causal, ¿no podría existir una estructura real que se correspondiese con esa predisposición?; ¿no podríamos adivinar una diferencia con ventajas evolutivas entre un post hoc y un propter hoc?. Vollmer presenta la siguiente tesis:

"La diferencia ontológica entre un post hoc (regular) y un propter hoc (causal) estriba en la transmisión de energía"136. Según Vollmer, en toda relación causal hay una transmisión de energía: de la causa al efecto y, en

132. G. Vollmer, art. cit. , pág. 62-63.

133. Ibidem.

134. Ibidem.

135. Ibidem.

136. G. Vollmer, art. cit., pág. 75 . 
algunos casos, del efecto a la causa. Así pues, "cada vez que hablemos coherentemente de la causalidad, de causa y efecto y de relación causal, hemos de poder comprobar también la correspondiente transmisión de energía"137.

\section{3.- Metodología popperiana.}

En este apartado pretendemos señalar lo más sintéticamente posible cuáles son los rasgos fundamentales de la teoría del conocimiento popperiana.

Tanto en $C . y$. como en su B. S. T. ${ }^{138}$ Popper explica cómo llegó a interesarse por el problema del conocimiento.

Frente al marxismo, la teoría del psicoanálisis de Freud y la "psicología del individuo" de Adler, estaba la teoría de Einstein.

En C. y R. nos dice que fue "el hecho de que yo sentía que esas tres teorías, aunque se presentaban como ciencias, de hecho tenían más elementos en común con los mitos primitivos que con la ciencia; que se asemejaban a la astrología más que a la astronomía"139. Estas teorías presentaban en común la característica de la verificación o confirmación. Todo caso singular encajaba en ellas como un hecho confirmatorio de la teoría.

Frente a estas tres teorías estaba la de Einstein ${ }^{140}$ que establecía predicciones arriesgadas, exponiéndose a la refutación si tales predicciones no se verificaban en la experiencia.

Así pues, podemos agrupar la metodología popperiana respecto a las exigencias de las teorías científicas, en torno a los siguientes puntos, sin tener en cuenta la evolución temporal de su pensamiento:

1. - Toda teoría debe tener una estructura hipotético-deductiva; por tanto, rechazo de la inducción.

2. - Debe explicar los fenómenos conocidos del campo estudiado y debe también predecir otros nuevos.

3. - Toda teoría debe someterse al riesgo de la falsación, especificando la forma en que podría ser refutada.

4. - Asimetría entre verificalidad y falsabilidad. Una teoría puede resultar refutada pero nunca puede ser verificada apodícticamente.

5. - Consideración de la Verdad como una idea reguladora en el sentido kantiano. Las teorías pueden compararse por su mayor o menor verosimilitud o semejanza a la verdad.

137. G. Vollmer, art. cit. , pág. 76.

138. K. Popper, C. y R. , pág. 57 y ss. y B. S. T. , pág. 43 y ss.

139. K. Popper, C. y R. pág. 59.

140. Véase a este respecto, C. y R. pág. 60 y B. S. T., pág. 50. 
6. - Lucha a muerte por la supervivencia entre teorías como si se tratara de especies vivientes (supervivencia darwiniana de los más aptos).

Otros temas de su teoría del conocimiento, y que luego discutiremos son:

7. - Realismo crítico. Aspiración en el conocimiento a una comprensión y descripción de la realidad.

8. - Determinismo indeterminismo.

9. - Análisis de la probabilidad, primero, como teoría de frecuencias, para en un segundo momento, hacer una interpretación de la probabilidad como una teoría de propensiones, con lo que se pretende salvar la fractura que existe entre el pensamiento y la realidad.

Nos detenemos brevemente en este apartado, en la inducción, en la falsación y en la famosa asimetría entre verificabilidad y falsabilidad.

Respecto al problema de la inducción Popper es claro: "El punto fundamental es la relación entre observación y teoría. Creo que la teoría siempre va delante de las observaciones... el papel de las observaciones es mostrar que algunas de nuestras teorías son falsas, estimulándonos a construir otras mejores... No partimos de observaciones, sino siempre de problemas: se puede conjeturar una solución... el aumento de conocimiento va de viejos a nuevos problemas mediante conjeturas y refutaciones"141.

El problema de la inducción consiste en cómo pasar de enunciados de experiencia a establecer enunciados universales. No hay posibilidad lógica de justificar la inducción. "Sin esperar pasivamente que las repeticiones impriman e impongan regularidades sobre nosotros debemos tratar activamente de imponer regularidades al mundo. Debemos de tratar de descubrir similaridades en él e interpretarlas en función de las leyes inventadas por nosotros. Sin esperar el descubrimiento de premisas debemos saltar a conclusiones. Estas quizás tengan que ser descartadas luego, si la observación muestra que están equivocadas. Se trata de una teoría de ensayo y error, de conjeturas y refutaciones"142.

Así pues, queda claro que nuestros intentos de comprender el mundo son anteriores, a las observaciones, y esto se aplica a las teorías científicas,

141. K. Popper, C. O., pág. 237- 238. Sobre la influencia de Einstein en la metodología popperiana podrían establecerse ciertas semejanzas. Sirva como ejemplo recordar las hipótesis sobre el éter y cómo estas fueron falsadas por la experiencia o por los hechos. (Cfr.: a este respecto, A. Einstein y L. Infeld, La física aventura del pensamiento, pág. 143-152, ed. Losada, Buenos Aires, 1961/6). También la página 169 de la misma obra. Sobre el criterio de falsabilidad, véase Ch. S. Peirce, Collected Papers, 1935. K. O. Apel atribuye a Ch. S. Peirce el principio de "falibilismo" en la introducción de su edición de Ch. S. Peirce Schüpten I und II, (Franfurt a. M. 1967 y 1970)

142. K. Popper, C. y R. pág. 72. 
que en vez de ser un conjunto de observaciones, se presentan como invenciones o conjeturas que deben ser ensayadas y eliminadas si fracasan por las observaciones.

La observación es siempre selectiva, presupone un interés y un problema. $\mathrm{Y}$ en esta línea se podría llegar a la existencia de expectativas inconscientes, innatas ${ }^{143}$. Nacemos con expectativas que, aunque no son válidas a priori, son psicológicamente o genéticamente a priori... como por ejemplo la necesidad de hallar regularidades.

La relación en este punto con Kant es evidente, ya que podría interpretarse toda la Analítica transcendental como el esfuerzo por superar las dificultades planteadas por Hume sobre la inducción. Y el mismo Popper lo reconoce en C. y R. : "El primer filósofo que captó claramente el enigma de la ciencia natural fue Kant" y "comprendió más claramente que nadie, antes o después de él, cuán absurdo es suponer que la teoría de Newton puede ser derivable de observaciones"144.

Una vez rechazado por Popper el principio de inducción, analizamos el tema de la falsación, ya que según él, debe ser el criterio que permita evaluar si una teoría debe ser o no aceptada dentro del estatuto científico. Para aceptar una teoría, aunque sólo sea provisionalmente, se necesita la aplicación del criterio de falsación: "sólo admitiré un sistema entre los científicos o empíricos si es susceptible de ser contrastado por la experiencia... El criterio de demarcación que hemos de aceptar no es el de verificabilidad sino el de falsabilidad de los sistemas... No exigiré que un sistema científico pueda ser seleccionado, de una vez para siempre, en un sentido negativo por medio de contrastes o pruebas empíricas; ha de ser posible refutar por la experiencia un sistema científico empírico"145.

También sobre este punto existe un texto kantiano como réplica a un crítico que se escondía en Noticias eruditas de Gotinga y que suele publicarse como apéndice a los Prolegómenos. Dice así:

"El mismo encuentra en estos prolegómenos y en mi Crítica, ocho proposiciones, cada dos de las cuales se contradicen recíprocamente, pero cada una de las cuales pertenece necesariamente a la metafísica, la cual debe aceptarlas o contradecirlas (aunque ninguna de ellas haya dejado de ser aceptada por algún filósofo). Ahora bien, el crítico tiene la libertad de elegir a su gusto una de estas ocho proposiciones y aceptarla sin prueba, puesto

143. K. Popper, C. y R. pág. 73.

144. K. Popper, C. y R., pág. 215-216. Puede verse sobre este apartado, M. Fartos Martínez, "Sobre la concepción kantiano-popperiana de la ciencia", en Naturaleza y Gracia, Vol. XXXIX/2-3, mayo-diciembre, 1992, Salamanca, 1992.

145. K. Popper, L. I. C., pág. 40. 
que de esto le dispenso; pero solamente una (pues tampoco útil ha de ser para él como para mi la pérdida de tiempo). Y entonces que ataque mi prueba de la antítesis. Pero si yo puedo salvar igualmente ésta y mostrar, de tal manera, que, según los principios que toda metafísica dogmática debe reconocer necesariamente, puede ser probado, de un modo igualmente claro, lo contrario de la proposición por él adoptada, está, pues, probado que en la metafísica hay una falta originaria, que no puede ser explicada, mucho menos resuelta, sin elevarse hasta el lugar de su nacimiento hasta la razón pura misma; y así, mi crítica debe, o ser aceptada o sustituida por otra mejor, pero al menos, pues, ser estudiada; lo cual es lo único que exijo ahora. Si yo no puedo por el contrario salvar mi prueba entonces se establece sólidamente, de parte de mi adversario, una proposición sintética a priori de principios dogmáticos; mi inculpación a la metafísica común será, por esto injusta y me obligo a reconocer como equitativa su censura de mi Crítica (Aunque esto no debería ser aún la consecuencia)"146.

Respecto a la asimetría entre verificabilidad y falsabilidad, es sorprendente comprobar la similitud que existe con el texto kantiano donde expone la asimetría entre demostraciones que proceden del modus ponens y aquellas que proceden del modus tollens ${ }^{147}$ :

"La verdadera causa del uso de demostraciones apagógicas en diferentes ciencias es ésta: cuando los fundamentos de los que se pretende derivar cierto conocimiento son demasiado numerosos o se hallan excesivamente velados, se ensaya la posibilidad de llegar a tal conocimiento a través de sus consecuencias. Sería el modus ponens, esto es, inferir la verdad de un conocimiento partiendo de la verdad de sus consecuencias, lo cual sólo es permisible cuando son verdaderas todas sus consecuencias. En efecto, sólo a un fundamento puede deberse este último caso, fundamento que, consiguientemente, es también él verdadero. Ahora bien, este procedimiento es impracticable, pues el ver todas las consecuencias de cualquier proposición que adoptemos es algo que excede nuestra capacidad. Este tipo de inferencia es, no obstante, empleado-si bien, naturalmente, con cierta indulgencia cuando sólo se trata de demostrar algo como hipótesis, admitiéndose entonces la conclusión en virtud de la analogía siguiente: si todas las consecuencias ensayadas concuerdan con un fundamento supuesto, todas las demás consecuencias posibles tienen que concordar igualmente con él. Por ello nunca se puede, por este camino, transformar una hipótesis en una verdad demostrada. El modus tollens de los razonamientos que van de las consecuencias a los

146. I. Kant, Prolegómenos. (Apéndice).

147. I. Kant, C. R. P., A. 791- B.819, pág. 621. 
fundamentos, no sólo demuestra rigurosamente, sino además, con gran facilidad, pues basta que pueda extraerse de una proposición una sola consecuencia falsa para que tal proposición sea también falsa. En vez de recorrer, pues, en una demostración ostensiva toda la serie de fundamentos que pueden conducirnos a la verdad de un conocimiento mediante una exhaustiva comprensión de su posibilidad, sólo necesitamos encontrar una sola consecuencia falsa entre las que derivan del conocimiento opuesto para que este opuesto sea también falso y para que, consiguientemente, sea verdadero el conocimiento que se trata de probar".

Si quisiéramos precisar más la teoría de.Popper debemos hacer referencia al realismo que defiende. En la pág. 49 de Conocimiento objetivo resume su posición sobre el realismo:

"Propongo aceptar el realismo como la única hipótesis sensata (como conjetura a la que nunca se ha opuesto una alternativa sensata). No quiero ser dogmático a este respecto, como a ningún otro, pero creo conocer todos los argumentos epistemológicos (fundamentalmente subjetivistas) que se han propuesto en favor de alternativas al realismo: el positivismo, el idealismo, el fenomenalismo, la fenomenología, etc... Aunque no me opongo a la discusión de los ismos filosóficos considero que todos los argumentos filosóficos que han sido propuestos (que yo sepa) en favor de esa lista de ismos son, sin duda, erróneos... Todos derivan de una teoría del conocimiento equivocada, aunque de sentido común que no resiste una crítica seria"148.

Frente a las diversas formas más o menos camufladas de idealismo, Popper defiende una teoría que puede ser y de hecho ha sido denominada realismo crítico. También conviene tener en cuenta que Popper se ha opuesto siempre al esencialismo.

Ya en la lógica de la Investigación científica ${ }^{149}$ y en relación al método científico exponía el siguiente requisito: que el sistema llamado ciencia empírica represente únicamente un mundo, el mundo real o el mundo de nuestra experiencia ${ }^{150}$.

En Conjeturas y Refutaciones ${ }^{151}$ plantea de nuevo el problema del realismo en el sentido de si son las teorías solamente instrumentos o son descripciones del mundo y lo hace en relación a Galileo que pensaba que una teoría es una descripción verdadera del mundo.

En esta obra pasa revista a tres concepciones del conocimiento. La primera es la explicación por esencias distinguiendo tres tipos de esencialismo:

148. K. Popper, Con. obj. pág. 248.

149. K. Popper, L. I. C., pág. 38.

150. Ibidem. Cfr. también el Apéndice X, pág. 392.

151. K. Popper, C. y R. pág. 130 y ss. 
1. "El científico aspira a hallar una teoría o descripción verdadera del mundo... que sea también una explicación de los hechos observables" (Este elemento será incorporado por Popper a su propia teoría).

2. "El científico puede establecer, finalmente, la verdad de tales teorías más allá de toda duda razonable"...

3. "Las mejores teorías, las verdaderamente científicas, describen las "esencias" o "naturalezas esenciales de las cosas, las realidades que están detrás de las apariencias"152. Los puntos dos y tres constituyen el esencialismo y la crítica que Popper hace a este planteamiento puede resumirse de la siguiente manera: Es cierto que hay mucho oculto, pero puede descubrirse; por otra parte, según su concepción de las teorías y de la verdad, la ciencia no tiene explicaciones últimas; además, no se niega que existan esencias, pero es algo indiferente respecto al problema analizado ${ }^{153}$.

Popper pasa revista también al instrumentalismo, para exponer finalmente su propia teoría. Considera los términos conjetura, verdad y realidad.

Con esta concepción se conserva la doctrina de Galileo en el sentido de aspirar a la verdadera descripción del mundo o de algunos de sus aspectos a la vez que a una explicación de los hechos observables, pero teniendo en cuenta que nunca podremos saber con certeza si los resultados son verdaderos, aunque sí podamos demostrar con razonable certeza que una teoría es falsa .

Las teorías científicas, nos dice Popper, "son genuinas conjeturas, suposiciones acerca del mundo de alto contenido informativo, y que, si bien no son verificables... pueden ser sometidas a severos test"154.

En Conjeturas y Refutaciones vuelve a precisar su punto de vista a través de los siguientes puntos:

1. "Es posible trabajar con algo similar a un mundo situado "detrás" del mundo de la apariencia sin comprometerse con el esencialismo"...

2. "Estas teorías no son hipótesis matemáticas, es decir, nada más que instrumentos para la predicción de apariencias".

3. "No hay ninguna apariencia pura u observación pura".

4. Toda observación contiene elementos teóricos o hipotéticos.

5. "Las nuevas teorías, además pueden dar origen a una reinterpretación de las viejas apariencias, y de este modo, cambiar el mundo de las apariencias".

152. K. Popper, C. y R. pág. 137. También se refiere a estas concepciones en C. O. pág. 183 y ss.

153. K. Popper, C. y R. pág. 138-139.

154. K. Popper, C. y R. , pág. 149. 
6. "La multiplicidad de teorías explicatorias... es utilizada, cuando ello es posible, para imaginar (con respecto a teorías rivales) condiciones en las que estas den resultados observables diferentes, de modo que podamos efectuar un test crucial para decidir entre ellas y ganar de este modo nueva experiencia"155.

Podemos ver efectivamente cómo la intención fundamental de Popper es la aspiración a teorías verdaderas, al progreso de la ciencia, si bien, nunca como hemos dicho tendremos la seguridad de haberlo conseguido. Lo único que es posible es el ir aproximándonos a la verdad.

Popper expone una serie de consideraciones a favor del realismo (o en contra del idealismo). Algunas de estas consideraciones se refieren a lo siguiente:

a) El realismo forma parte del sentido común.

b) Los argumentos contra el realismo son filosóficos en el peor sentido de la palabra y además se basan en un sentido común aceptado acríticamente.

c) Considera la importancia de la ciencia para el realismo. Si la ciencia es verdadera, el realismo debe serlo en la misma medida, ya que lo que la ciencia pretende es describir el mundo y en cuanto es posible explicar la realidad.

d) Recurre también a argumentos lingüísticos refiriéndose a la función descriptiva del lenguaje. Se pretende describir algo.

e) Decir que el mundo es una creación mía es un absurdo ${ }^{156}$.

También en este contexto hace referencia a la idea kantiana de las categorías a priori pero dentro del marco evolutivo. En efecto, pretendemos imponer al mundo nuestras leyes a priori (dadas genéticamente). Pero no son válidas a priori. De hecho muchas veces fracasan. Así pues, nuestro conocimiento progresa por conjeturas y refutaciones.

Por lo que venimos diciendo puede advertirse el drama kantiano-popperiano de la ruptura entre el pensamiento y la realidad.

La solución de Popper a esta inmensa dificultad pasa por la teoría de la probabilidad. De ella da dos interpretaciones: la frecuencial y la de las propensiones. No hay contradicción entre ellas sino complementariedad.

En el análisis de la probabilidad distinguimos dos planos ${ }^{157}$ :

a) Construcción matemática (teórica) de las series (sin ninguna imposición de la experiencia) y

b) El plano de la realidad empírica (series azarosas).

155. K. Popper, C. y R., pág. 216-217.

156. K. Popper, C. O., pág. 49.

157. K. Popper, L. I. C., pág. 137-200. 
El problema que se plantea es cómo es posible el ajuste o adecuación entre la serie matemática (teórica) y la secuencia azarosa (realidad).

Basta considerar para ello que la serie empírica es uno de los segmentos de la serie matemática y conjeturar desde ella cuál sería la continuación de la empírica. Se trata de sustituir la serie empírica por la construcción matemática. No construimos teorías a partir de la experiencia (inducción). Todo lo que conocemos viene dado por el propio acto de conocer, es estructurado por la razón que conoce. La realidad queda asumida como un segmento de la teoría. Esto nos obliga a suponer que la teoría funciona como la realidad. Si hay desacuerdo, abandonamos la teoría. Esta es la búsqueda sin término: lanzar conjeturas y eliminar los errores. Imponemos nuestras leyes a la naturaleza, pero no necesariamente con éxito como pensaba Kant, sino de forma siempre provisional ${ }^{158}$.

Como complemento a la teoría frecuencial de la probabilidad está la interpretación de la probabilidad como propensión: Esto significa que las probabilidades son físicamente reales. Se trata de propensiones físicas. Son propiedades disposicionales que se manifiestan en las diversas situaciones experimentales. Son propiedades relacionales ${ }^{159}$.

$\mathrm{Y}$ aquí es donde se establece el puente entre el pensamiento y la realidad: existen propensiones en las cosas y nosotros estamos en disposición de conocerlas. Esto nos lleva a comprender la verosimilitud y la evolución.

En cuanto a la verosimilitud, diríamos que el pensamiento se construye desde sí mismo, que existe una realidad objetiva fuera de él y a la que nos vamos acercando progresivamente. Habría como un paralelismo entre el pensamiento y las propensiones o tendencias de la realidad.

En cuanto a la evolución, le sirve para comprender la existencia de las categorías mentales ${ }^{160}$.

\section{4.- Las teorías cognitivas y el procesamiento de la información.}

No queríamos dejar esta exposición sin hacer una referencia, aunque breve, a las teorías cognitivas ${ }^{161}$. Como es sabido, el conductismo fue la escuela dominante desde 1913 hasta los años 30. Evoluciona luego como

158. Sobre esta problemática Cfr.: A. Pérez de Laborda, ¿Salvar lo real?, Encuentro, Madrid, 1983, cap. VII, pág. 315-335. 318-340.

159. K. Popper, Realismo y el objetivo de la ciencia, Tecnos, Madrid, 1985, parte II, pág.

160. Este aspecto lo hemos tratado ya en L. Velázquez Campo, Teoría evolutiva del conocimiento y metodología popperiana, en Est. Agust. Vol. XXVI, Fasc. I, 1991, Valladolid, pág. 131-152.

161. Sobre este apartado cfr.: Fernández Trespalacios, Psicología general II, y Soledad Ballesteros. 
neoconductismo con todas las dificultades que fueron surgiendo. (Uno de sus más firmes enemigos fue Chomsky, que colabora e influye en la crisis y descomposición del conductismo).

Los orígenes de la Psicología cognitiva pasan por Turing (1936), por los trabajos de Wiener y von Neumann y sus estudios sobre cibernética y el modelo de neurona de McCulloch y Pitts (1943). Estos dos últimos autores desempeñan un papel importante en el surgimiento de la ciencia cognitiva al establecer que el cerebro humano actúa como una potentísima computadora que se rige por el principio de "todo o nada" operando de forma semejante a los principios de la lógica.

Es preciso destacar también la obra y aportación de Shannon(1948) con su teoría completa de la información.

A través de todas estas aportaciones a las que yo sólo aludo, por los años cincuenta se advierte un descontento creciente contra el conductismo que seguía planteando un marco de investigación excesivamente restringido y asfixiante y que cristaliza en los años sesenta en la Psicología cognitica.

Uno de los elementos fundamentales de la teoría cognitiva es el de la representación mental. Se pretende comprender la naturaleza de dicha representación. Se formulan para ello una gran variedad de teorías, lo que viene a significar que existe una gran dispersión conceptual al respecto. Nosotros pensamos después de recorrer toda esta variedad, que, por lo que respecta a la psicología, que evidentemente quiere tener un estatuto científico, cosa que en muchos temas dudamos haya conseguido, se adhiere con demasiada premura a ciertos paradigmas que, en principio, son prometedores, pero que no llegan a constituirse en rutas sólidas y definitivas.

Pese a esta dispersión, es indudable la utilidad de haber postulado el nivel de representación mental en cuanto que nos permite comprender una serie de fenómenos mentales.

Los fenómenos mentales no se reducen a conexiones mediacionales estímulo-respuesta, sino que pueden ser procesos y estructuras diferentes. Esta teoría postula también una serie de operaciones que hacen posible el uso de las representaciones mediante la activación de determinados procesos.

En Psicología cognitiva, pese a la dispersión de teorías, podemos señalar tres alternativas principales.

En primer lugar, está el nuevo estructuralismo, que quiere ser un paradigma que unifique el campo de las ciencias sociales y al que se adhieren filósofos, antropólogos, psicólogos y lingüistas. Cito a Piaget, que pretende en la línea racionalista platónico-cartesiana, hacer una descripción de la mente humana transcendente. Lo que le importa es la persona como sujeto cognoscente abstracto.

La segunda altermativa se refiere a la metáfora del ordenador y al procesamiento de la información. 
Se supone que a través del sistema sensorial se capta información del ambiente que pasa a disposición de la mente (de la misma manera que el ordenador recibe el input de los sistemas periféricos).

En un segundo momento, esta información es manipulada a través de procesos mentales y la transforman al igual que hace el ordenador aplicando las reglas de su sintaxis.

$\mathrm{Y}$, en tercer lugar, la mente produce la información que se manifiesta en la conducta (En el ordenador sale a través de la impresora).

La idea fundamental del procesamiento de la información (cito de $\mathrm{S}$. Ballesteros, 1993) es que "la mente funciona como un tipo de programa de ordenador en el que cualquier evento informacional complejo puede descomponerse y especificarse en un nivel más bajo. La información se encuentra almacenada en los estados del sistema llamados representaciones que son utilizados mediante la puesta en funcionamiento de diferentes procesos psicológicos".

El simulacionismo, llamado también computacionalismo o inteligencia artificial "débil", "mantiene que la correspondencia "input-output" es una función computable". Escriben programas de ordenador que simulen la conducta humana. El ordenador se entiende como un instrumento útil que permita descubrir la naturaleza de los procesos mentales. Sin embargo, no asume que la máquina tenga procesos mentales.

La posición más radical es el funcionalismo de la máquina de Turing (inteligencia artifical "fuerte"), "que defiende que si un ordenador debidamente programado tiene la misma organización funcional e implementa los mismos algoritmos que la mente humana, esta máquina tendrá mente y poseerá en realidad los estados mentales que simula"(Ibidem).

Existe una variante de inteligencia artificial en el momento actual y es el modelo cognitivo que se denomina conexionismo que pretende explicar la cognición como la interacción simultánea de unidades semejantes a neuronas inmensamente interconectadas entre sí. No admiten el procesamiento en serie, sino que hablan de un procesamiento paralelo distribuido defendiendo a su vez el modelo cerebral de la mente.

La tercera alternativa es el nuevo mentalismo de F. Breuler y J.C. Bransfora: percibimos no frases, sino ideas centrales y esquemas básicos.

\section{5.- Una aproximación desde la ciencia neurobiológica al fenómeno del conocimiento}

Neurobiología de la visión

Hemos elegido el tema de la visión para acercarnos al conocimiento desde la neurobiología por ser uno de los mecanismos de nuestro cerebro 
mejor conocidos en la actualidad, teniendo en cuenta que, desgraciadamente, se desconocen todavía demasiadas cosas de nuestro córtex cerebral.

En los apartados anteriores hemos considerado las diversas interpretaciones filosóficas del conocimiento humano. ¿Será válida la afirmación de F. H. C. Crick ${ }^{162}$ que "la filosofía ha sido en gran parte estéril durante más de 2.000 años y probablemente seguirá siéndolo hasta que los filósofos aprendan a entender el lenguaje del proceso de la información"?.

Nosotros partimos de la convicción de que, antes de la interpretación y discusión filosófica de un problema, es necesario disponer de los datos científicos más fiables sobre el fenómeno que queremos analizar.

Se nos permitirá, por tanto, que expongamos, aunque demasiado resumidos, los resultados científicos que están a nuestro alcance. Me baso, sobre todo, en el artículo de David Hubel y Torsten N.Wiesel, "Mecanismos cerebrales de la visión", publicado en el monográfico El cerebro, de Investigación y ciencia ${ }^{163}$.

Uno de los grandes logros de la evolución ha sido la aparición del córtex cerebral que alcanza su mayor desarrollo en el hombre, 1.400 centímetros cuadrados si se extendiera, y que posee unos 10.000 millones de neuronas.

El córtex, por otra parte, ha sido cartografiado especificando las diferentes áreas responsables de la representación que hacemos del mundo. Nosotros, aquí, nos vamos a referir al córtex visual primario o área 17.

¿Cómo analiza nuestro cerebro la información que le llega? Veamos el recorrido que se realiza desde la retina hasta el córtex.

Nuestra retina consta de tres capas de células nerviosas. La más externa posee unos cien millones de células fotorreceptoras que son de dos clases, los bastones y los conos. Las señales luminosas se transforman en señales eléctricas. De esta forma, el patrón de luz y oscuridad de la imagen visual es transformado mediante los receptores de la retina en un patrón bidimensional de actividad eléctrica. Por vía sináptica, las señales de las células fotorreceptoras se transmiten a las células bipolares que a su vez, también, por vía sináptica, pasan a las células ganglionares retinianas. Cada célula ganglionar (y hay aproximadamente un millón de ellas) recoge las impresiones sensoriales de unas cien células fotorreceptoras. Cada uno de estos grupos ocupa una

162. F. H. C. Crick, "Reflexiones en torno al cerebro", en El cerebro, Invest. y Cien, Barcelona, 1986, pág. 223 (220-228).

163. D.H.Hubel y T. N. Wiesel, “Mecanismos cerebrales de la visión”, en Inv.y Cien., El cerbro, Barcelona, 1986 (114-128). Utilizo también el capítulo 2 (E.2) de J.Eccles, "La percepción consciente", 10.- Percepción visual, en K.Popper y J.Eccles, El yo y su cerebro, Labor, Barcelona. 1980. Puede consultarse también, el monográfico de Investigación y Ciencia, Mente y cerebro, Barcelona 1993, y en especial sobre la visión, el artículo de Semir Zeki, "La imagen visual en la mente y en el cerebro", pág. págs. 36-46. 
zona circular de la retina. La tarea de las células ganglionares consiste no en evaluar los niveles de iluminación "sino (en) comparar el nivel de luz en una zona pequeña de la escena visual con la iluminación media de la periferia inmediata"164.

Se produce así el primer nivel de "abstracción": "La información sobre la distribución de intensidades luminosas en 100 millones de puntos, recogida por las células fotorreceptoras, es reducida por las células ganglionares a una estimación de los contrastes de luz en un millón de áreas circulares"165. Un millón de fibras nerviosas (axones) procedentes de las células ganglionares forman el nervio óptico y transmiten la información al cerebro y allí seguirá siendo procesada. En el quiasma óptico se encuentran el nervio óptico del ojo derecho con el del ojo izquierdo. Aquí las fibras de cada nervio óptico se dividen en dos mitades, constando cada una de medio millón de axones.

En el quiasma óptico se produce un entrecruzamiento. "Las hemirretinas de ambos ojos (nasal del derecho y temporal del izquierdo) que reciben la imagen del campo visual derecho, reorganizan en el quiasma las proyecciones de su nervio óptico, uniéndose para formar la vía a la corteza visual izquierda, y viceversa, por lo que respecta al campo visual izquierdo, que se proyecta a la corteza visual derecha. Así, con excepción de una estrecha banda vertical (meridional) del campo visual, que se encuentra directamente en la línea de visión, el conjunto de imágenes visuales de los campos derecho e izquierdo van respectivamente a las cortezas visuales izquierda y derecha para formar un mapa ordenado".... ${ }^{166}$.

Las fibras del nervio óptico pasan al núcleo geniculado lateral. Se trata de dos núcleos geniculados simétricos en el encéfalo. "Cada fibra del nervio óptico envía el patrón de actividad eléctrica de una célula ganglionar retiniana a una o más células del núcleo geniculado lateral. A su vez, las células del núcleo geniculado lateral envían sus axones, formando un haz, a la parte posterior (occipital) de la corteza cerebral, la corteza visual, encargada del ulterior procesamiento del registro visual"167. Los axones del núcleo geniculado lateral establecen contactos sinápticos con las neuronas del área 17. La imagen creada en la retina conserva su coherencia topológica en el área 17. Desde este área existen proyecciones adicionales hacia las áreas 18 y 19 conservándose en ellas la coherencia topológica. La información pasa a otras 109.

164. D. H. Hubel y T. N. Wiesel, art. cit., pág. 118. También, Max Delbrück, op. cit , pág.

165. M. Delbrück, op. cit., pág. 110.

166. K. Popper y J. Eccles, El yo y su cerebro, pág. 296.

167. M. Delbrück, op. cit., pág. 110. 
áreas corticales, pero ya se pierde parte de la coherencia topológica, tal vez porque ya se ha extraído lo fundamental de los elementos de la imagen ${ }^{168}$.

¿Cómo se realiza la reconstitución de la imagen visual?. Según J. Eccles $^{169}$, citando a Hubel y Wiesel (1963) "en la corteza visual las neuronas con una orientación similar tienden a estar dispuestas en columnas que discurren ortogonalmente respecto a la superficie cortical. Por lo tanto, se puede considerar que, en la gran área de la corteza visual primaria, la población de unos cuatrocientos millones de neuronas se encuentra dispuesta en un mosaico de columnas, cada una de las cuales presenta unos cuantos de miles de neuronas con sensibilidad igualmente orientada... Esta disposición se puede considerar el primer estadio de reconstitución de la imagen retiniana".

Si consideramos mentalmente el esquema de la ruta visual podemos ver cómo el mapa del área de la corteza visual se superpone al mapa del campo retiniano, "estando compuesta cada una de las zonas de este campo por columnas, que, en conjunto, representan todas las orientaciones de líneas brillantes o de aristas entre claridad y oscuridad"170.

Un segundo estadio de la reconstitución de la imagen acontece en las áreas 18 y 19. Existen en estas áreas neuronas especialmente sensibles a la longitud y anchura de las líneas claras y oscuras, así como a su orientación e incluso a dos líneas que formen un ángulo. Estas neuronas llamadas complejas e hipercomplejas (Hubel y Wiesel) constituyen un ulterior estadio de reconocimiento. Se cree que estas neuronas "complejas" e "hipercomplejas" adquieren sus propiedades específicas mediante una síntesis de los circuitos neuronales activados por células "simples", los cuales contienen componentes tanto excitadores como inhibitorios ${ }^{171}$.

La información visual pasa a las áreas 20 y 21. ¿Cómo puede recobrarse la especificidad del campo en estos estadios ulteriores?

Reproduzco sintéticamente la respuesta de Eccles: "Puede considerarse que cada estadio de procesamiento de información visual, desde la retina a

168. Para conocer las conexiones de las diferentes áreas se han empleado diversos métodos:a) Se causan lesiones nerviosas localizadas y se buscan las zonas en que aparecen fibras nerviosas degeneradas.b) Se inyecta un aminoácido marcado radiactivamente en una zona del sistema nervioso, lo que permite seguir la ruta.c) El inverso del anterior: Se inyecta peroxidasa de rábano en una región del sistema nervioso para localizar las células de donde salen las fibras nerviosas.d) Para descubrir las conexiones se utilizan también métodos electrofisiológicos. Cfr.: Hubel y Wiesel, art. cit., pág.118 y ss.).

169. J. Eccles, El yo y su cerebro, pág. 299.

170. J. Eccles, El yo y su cerebro, pág. 300.

171. Ibidem. Cfr. : Art. cit. , de Hubel y Wiesel, pág. 120. 
las áreas corticales 20 y 21, posee un orden jerárquico con características en orden secuencial:

1) El campo visual se torna progresivamente menos específico. La creciente generalización produce una representación foveal para todas las neuronas de las áreas 20 y 21 . Además, en este estadio, todas las neuronas reciben información de ambos hemicampos visuales, incluyendo la fovea, mediante impulsos a ambos lóbulos occipitales, pasando por el splenium del cuerpo calloso.

2) Hay un aumento de especificidad del estímulo adecuado, desde una mancha hasta una arista o línea brillante de una orientación particular; de esto a líneas de longitud y anchura especificadas, a menudo con especificación de la dirección del movimiento; y finalmente, a la detección de características más complejas de algunas neuronas de las áreas 20 y 21.

3) También existen pruebas de que las neuronas de las áreas 20 y 21 poseen una característica de respuesta adicional; a saber, la significación que tiene la respuesta para el animal, exactamente del mismo modo que se ha descubierto en el caso de neuronas de las áreas 5 y 7 del sistema somestésico (Mountcastle, 1975) ${ }^{172}$. Pero todos estos descubrimientos siguen sin ofrecernos la respuesta de cómo se reconstruye la imagen visual completa a través del entramado neuronal del cerebro. J. Eccles, teniendo en cuenta los resultados de Weiskrantz (1974), Penfield y Sarper (1954) y otros señala que "los grandes logros de la investigación de la visión tan sólo se pueden considerar el primer paso hacia la explicación de cómo acaba reconstituyéndose como imagen observada aquella imagen de la retina, codificada en forma de descargas neuronales"173. En el capitulo E7 de esta misma obra, Eccles propone una hipótesis radical como una nueva filosofía de la percepción donde aborda los problemas de unidad y orden secuencial. Podríamos concluir a partir de los datos que nos ofrece la neurobiología que nos hallamos ante un "realismo estructuralista". Tal posición no niega que exista un mundo fuera del sujeto. Pero aquello que nosotros percibimos es una estructura abstracta construida y elaborada a partir de los datos sensoriales y cuya correspondencia con la realidad se presupone, si bien no la podemos demostrar. Y aquí volvemos a encontrarnos con Kant (si bien, la neurobiología no dirá que los a prioris estén totalmente formados antes de nacer, lo que sí se da es una interacción dialéctica entre el sistema nervioso y el mundo exterior).

172. J. Eccles, op. cit. , pág. 303.

173. J. Eccles, op. cit. , pág. 305. Cfr. : Hubel y Wiesel, art. cit. , pág. 127-128. 


\section{Consideraciones críticas}

Hemos repasado algunas de las corrientes, a nuestro juicio, más significativas sobre el a priori del conocimiento. Una vez realizado este repaso histórico quisiéramos exponer los resultados a los que hemos llegado. Ni que decir tiene, que, dada su complejidad, no pretendemos sino una mínima aportación al problema de la comprensión del conocimiento en función de los datos que en el momento actual poseemos.

Nosotros estimamos que el punto de partida de la reflexión debe ser siempre el doble aspecto, dato científico e historia del problema (en este caso, filosófica). Se trata, por tanto de analizar cada uno de estos resultados para ver su posible armonización e integración. Ahora bien, cada uno de estos niveles presenta sus limitaciones. Por lo que se refiere a la filosofía, podemos ver cómo aparte de que cada explicación queda limitada por los intereses ideológicos de cada momento y por los modelos mentales, hay que añadir también la limitación que le viene por el grado de conocimiento científico del momento.

Pero la ciencia también evoluciona. De hecho, hoy mismo nos encontramos todavía con grandes limitaciones como hemos visto en el apartado de la neurobiología de la visión. En efecto, hay un momento dentro ya de las áreas cerebrales en el que perdemos la ruta de la señal nerviosa, y seguimos sin poder establecer qué es lo que sucede en las áreas sucesivas para que se de la reconstrucción del objeto. Esto no es óbice para que estas aportaciones sean indispensables y nos lleven a replantearnos en qué momento nos encontramos ahora.

Así pues, recapitulando cuanto hemos dicho, podemos establecer una serie de resultados, que en alguna manera pueden ser armonizados en una teoría coherente.

En términos generales, podemos advertir que todos los autores expuestos admiten una especie de lógica universal que el individuo posee de forma innata. Quítese a Platón el aspecto mítico de su teoría y nos encontraremos, como hemos señalado, con esa lógica universal que se descubre a través del lenguaje. Santo Tomás hablará de la capacidad (participada) por el entendimiento superior, que le permite al alma realizar en acto los inteligibles. En Ockam se habla de preordenación estructural de la facultad cognoscitiva que nos permite abordar significativamente la realidad exterior y que reacciona espontáneamente ante la presencia activa de esa misma realidad como un signo natural lingüístico. En Descartes, con la facultad innata de formar ideas. Para Leibniz el alma contiene originariamente las razones iniciales de diferentes conceptos y doctrinas y que sustentan las verdades de las matemá- 
ticas, de la lógica, de la metafísica y de la moral. En Kant, que entendía que no todo conocimiento se origina ni se funda en la experiencia (existen elementos a priori), aunque sí establece que todo conocimiento debe ser confirmado por la experiencia. En Husserl, en quien vemos cómo las ideas y los valores se convierten en las unidades ideales de significación a priori siendo unificadas en la conciencia. En Chomsky, se traduce este problema a través de la competencia lingüística. También en Vollmer y en Popper se dan por supuestas estas categorías como formas a priori del pensar. Las teorías cognitivas admiten también diversas estructuras que filtran, procesan y almacenan la información.

El problema, evidentemente, es saber cuál es la naturaleza de este a priori y cómo se haya originado.

$\mathrm{Si}$ analizamos en profundidad qué es lo que se ha conseguido con las anteriores aportaciones de la filosofía respecto a la naturaleza de este a priori, casi deberíamos constatar que apenas algo más que decir que existe y nombrarlo. Ninguna de las teorías citadas explica cómo acontece cuanto dicen. Ni siquiera la neurobiología ofrece una respuesta adecuada, al menos por ahora. Bien es verdad que si nos dirigimos a la física actual, tampoco especifica demasiado sobre los últimos componentes de la materia, dando la impresión en ocasiones que se haya caído en consideraciones de tipo más bien metafísico o místico.

Una segunda cuestión se refiere al origen del a priori.

Dada por supuesta la existencia del a priori como condición de posibilidad del conocimiento, de lo que se trata es de ver si es verosímil armonizar esta existencia con las explicaciones acerca del origen.

La validez de cuanto afirman la teoría evolutiva del conocimiento y la metodología de Popper presupone, al menos, dos acotaciones:

1) En la medida en que ambas posiciones se apoyan en las diferentes disciplinas (evolución, etología, Gestalt, lingüística, etc.,), su validez queda condicionada por el "status científico" de las mismas. En especial, habrá que tener en cuenta las críticas y los puntos oscuros del darwinismo y la situación problemática por la que hoy atraviesa dicha teoría.

2) La exposición del darwinismo que hace Popper se refiere a la teoría sintética de los años cuarenta y, en relación a ella establece su metodología evolucionista. Pero se puede advertir una doble contradicción: se apoya más en el lamarckismo para justificar la emergencia y, a la vez, no tiene en cuenta el desarrollo del neodarwinismo con el que entroncaría mejor su interpretación. Al mismo tiempo, surge la duda de si el neodarwinismo último es todavía realmente darwinista, en cuanto que dejan de tener importancia significativa los principios básicos del darwinismo. 
Teniendo esto en cuenta, vemos cómo la epistemología evolutiva (seguimos refiriéndonos a Vollmer) explica la formación de las categorías como el resultado de la evolución biológica. El ajuste entre las estructuras objetivas del mundo y las estructuras cognoscitivas del sujeto es posible, porque tales estructuras se han ido formando en la adaptación al mundo y de hecho, sólo ese ajuste hizo posible la supervivencia. Esta adaptación no llega a ser nunca total.

Así como para Kant el a priori es independiente de toda experiencia, para la epistemología evolutiva es independiente de toda experiencia indivi$d u a l$, pero producto del proceso evolutivo. Es un a posteriori filogenético. $\mathrm{Y}$ además, no es absolutamente válido: El hombre no es ya legislador de la naturaleza (Kant), sino simplemente observador del mundo.

Por otra parte, esta epistemología entiende las leyes del conocimiento y del lenguaje como algo no necesario tal y como son, viéndolas sólo dependiendo de las condiciones iniciales. Nosotros pensamos con Platón, Leibniz y Kant, que el pensamiento presupone una lógica absoluta, lleguemos o no a traducirla de forma adecuada.

Respecto al realismo que aquí se defiende, ya hemos visto que se denomina hipotético. Reconstruimos en nuestro cerebro las estructuras reales de forma tentativa. La objetividad de nuestro conocimiento del mundo puede establecerse a través de la intersubjetividad, de la comprensión pública (intersubjetiva), de la independencia ante el sistema del observador, de la comprobabilidad intersubjetiva, de la independencia ante el método y de la independencia ante las convenciones.

En estas dos teorías nos encontramos con el problema típicamente kantiano: la fractura entre pensamiento y realidad. Es cierto que ambas posiciones se plantean el problema del conocimiento como una forma de adaptación y de supervivencia (lo que no se puede identificar sin más como una concepción utilitarista, por lo menos en el caso de Popper). ¿Cómo consigue superar estas concepciones la ruptura entre pensamiento y realidad?.

En la biología del conocimiento esto se consigue en cuanto que se presupone que el viviente copia en su aparato cognoscitivo las estructuras de la realidad (se habla incluso de un isomorfismo parcial). La copia de tales estructuras es el resultado de un aprendizaje de especie a lo largo de la evolución mediante un proceso inductivo-deductivo que lleva, a través del ensayo y el error, a la codificación genética de las estructuras del mundo. En la probabilidad de acierto radica la supervivencia.

La fundamentación del conocimiento es de tipo pragmático: si el viviente se adapta, sobrevive y, puesto que hay millones de especies que han sobre- 
vivido, esto garantiza lo ajustado del conocimiento (otra cosa es el posible círculo vicioso de este tipo de argumentación).

La metodología de Popper quiere ser evolucionista, y, en cierto sentido lo es. Pero, al optar por el contexto de justificación y encerrarse en una metodología deductiva, renunciando a lo que podríamos denominar el contexto de descubrimiento y a las cuestiones sobre el origen (por miedo a caer en el psicologismo y por buscar el conocimiento objetivo) se pierde el núcleo de lo que debe ser una epistemología evolucionista.

Otro de los resultados que quisieramos destacar aquí relacionado con la superación de la ruptura entre pensamiento y realidad y donde ambas posiciones pueden interrelacionarse, es el siguiente: Las propensiones de Popper y el Mundo 3 como producto de la evolución y del lenguaje son los elementos que nos permiten superar la ruptura entre pensamiento y realidad. Nuestras teorías aciertan (la mayor parte de las veces, si no, no hubiéramos sobrevivido) en cuanto que se admite que nuestra forma de pensar es la transcripción genética de las mismas propensiones o de las estructuras fundamentales de las cosas. Imponemos nuestras leyes al mundo en cuanto que él las ha impuesto primero en nuestro aparato cognoscitivo, o en cuanto nuestro aparato cognoscitivo es el resultado de copiar tales estructuras( Ya hemos precisado también este concepto de "copia").

Así pues, la evolución sería la causa de todos los niveles del conocimiento, incluidas la razón, y el criterio último de todo este desarrollo sería la supervivencia. Ahora bien, una vez que se desarrolla la razón y el Mundo 3, comienza un proceso de retroalimentación sobre la misma evolución intentando superar las contradicciones entre nuestras teorías y la realidad.

Nos encontramos con una nueva paradoja en Popper: por una parte, busca el conocimiento objetivo y éste, en último término, está en la pura racionalidad. En este empeño sigue el modelo platónico y kantiano, el modelo de la ciencia desde el siglo XVII: sólo comprendemos el mundo sensible desde el mundo inteligible; sin embargo, desde el momento en que quiere ser realista, debe recurrir al modelo aristotélico en el que el hombre, su inteligencia, que es capaz de dar explicaciones y que construye el Mundo 3 , quiere captar la realidad, el mundo de nuestra experiencia. Y aquí nuevamente volvemos a las propensiones y a la evolución como forma de salvar el realismo.

Nuestro objetivo es la verdad, aunque nunca podamos conocerla totalmente o incluso saber que la hemos conocido; pero nos podemos ir aproximando a ella. Toda nuestra vida deberá ser "una búsqueda sin término".

Es aquí donde surge el problema kantiano-popperiano de la ruptura entre pensamiento y realidad y donde Popper intenta una solución aunque 
sea de emergencia, o más bien, diríamos que establece una posible solución que no desea llevar al límite: me refiero a la interpretación que hace de la probabilidad como propensión. A través de ella se supera la ruptura entre el pensar y el ser, ya que, al existir en las cosas las propensiones reales (aunque sean relacionales, Popper rechaza el esencialismo), nuestras conjeturas pueden alcanzar, en parte, la realidad. Lanzamos conjeturas que a veces aciertan y precisamente lo hacen en la medida en que estas expresan y se corresponden con las tendencias, disposiciones o propensiones que existen en las mismas cosas. Nos aproximamos a la verdad en la medida en que nuestras conjeturas son la expresión del comportamiento de la realidad de la que podemos conocer sus tendencias o propensiones. Y aquí es donde surge para Popper la necesidad de la teoría de la evolución y donde se complementa su posición con la de la biología.

Por cuanto hemos dicho, consideramos que los a prioris del conocimiento encuentran un soporte suficiente tanto en la neurobiología como en la epistemología evolucionista, a la vez que nos ofrecen sugerencias interesantes para seguir investigando sobre estas cuestiones. 